\title{
Effects of partial mixed rations and supplement amounts on milk production and composition, ruminal fermentation, bacterial communities, and ruminal acidosis
}

\author{
H. M. Golder, ${ }^{*}{ }^{1}$ S. E. Denman, $\ddagger$ C. McSweeney, $\ddagger$ W. J. Wales,§ M. J. Auldist,§ M. M. Wright,§ L. C. Marett,§ \\ J. S. Greenwood,§ M. C. Hannah,§ P. Celi, *\# E. Bramley,Il and I. J. Lean*† \\ *The Dairy Science Group, Faculty of Veterinary Science, The University of Sydney, Camden, New South Wales, Australia 2570 \\ †SBScibus, Camden, New South Wales, Australia 2570 \\ ¥CSIRO Animal, Food and Health Services, Queensland Bioscience Precinct, St. Lucia, Queensland, Australia 4067 \\ §Farming Systems Research Division, Department of Environment and Primary Industries, Ellinbank, Victoria, Australia 3821 \\ \#Melbourne School of Land and Environment, The University of Melbourne, Parkville, Victoria, Australia 3010 \\ IISchool of Veterinary and Biomedical Sciences, Murdoch University, Murdoch, Western Australia 6150
}

\section{ABSTRACT}

Late-lactation Holstein cows $(\mathrm{n}=144)$ that were offered $15 \mathrm{~kg}$ dry matter $(\mathrm{DM}) / \mathrm{cow}$ per day of perennial ryegrass to graze were randomized into 24 groups of 6 . Each group contained a fistulated cow and groups were allocated to 1 of 3 feeding strategies: (1) control (10 groups): cows were fed crushed wheat grain twice daily in the milking parlor and ryegrass silage at pasture; (2) partial mixed ration (PMR; 10 groups): PMR that was isoenergetic to the control diet and fed twice daily on a feed pad; (3) PMR+canola (4 groups): a proportion of wheat in the PMR was replaced with canola meal to produce more estimated metabolizable protein than other groups. Supplements were fed to the control and PMR cows at $8,10,12,14$, or $16 \mathrm{~kg}$ of $\mathrm{DM} / \mathrm{d}$, and to the PMR+canola cows at 14 or $16 \mathrm{~kg}$ of $\mathrm{DM} / \mathrm{d}$. The PMR-fed cows had a lower incidence of ruminal acidosis compared with controls, and ruminal acidosis increased linearly and quadratically with supplement fed. Yield of milk fat was highest in the PMR+canola cows fed 14 or $16 \mathrm{~kg}$ of total supplement $\mathrm{DM} / \mathrm{d}$, followed by the PMR-fed cows, and was lowest in controls fed at these amounts; a similar trend was observed for milk fat percentage. Milk protein yield was higher in the PMR + canola cows fed 14 or $16 \mathrm{~kg}$ of total supplement $\mathrm{DM} / \mathrm{d}$. Milk yield and milk protein percentage were not affected by feeding strategy. Milk, energy-corrected milk, and milk protein yields increased linearly with supplement fed, whereas milk fat percentage decreased. Ruminal butyrate and D-lactate concentrations, acetateto-propionate ratio, (acetate + butyrate)/propionate, and $\mathrm{pH}$ increased in PMR-fed cows compared with controls for all supplement amounts, whereas propionate

Received February 13, 2014.

Accepted May 16, 2014.

${ }^{1}$ Corresponding author: heleng@sbscibus.com.au and valerate concentrations decreased. Ruminal acetate, butyrate, and ammonia concentrations, acetate-topropionate ratio, (acetate + butyrate)/propionate, and $\mathrm{pH}$ linearly decreased with amounts of supplement fed. Ruminal propionate concentration linearly increased and valerate concentration linearly and quadratically increased with supplement feeding amount. The Bacteroidetes and Firmicutes were the dominant bacterial phyla identified. The Prevotellaceae, Ruminococcaceae, and Lachnospiraceae were the dominant bacterial families, regardless of feeding group, and were influenced by feeding strategy, supplement feeding amount, or both. The Veillonellaceae family decreased in relative abundance in PMR-fed cows compared with controls, and the Streptococcaeae and Lactobacillaceae families were present in only minor relative abundances, regardless of feeding group. Despite large among- and withingroup variation in bacterial community composition, distinct bacterial communities occurred among feeding strategies, supplement amounts, and sample times and were associated with ruminal fermentation measures. Control cows fed $16 \mathrm{~kg}$ of DM of total supplement per day had the most distinct ruminal bacterial community composition. Bacterial community composition was most significantly associated with supplement feeding amount and ammonia, butyrate, valerate, and propionate concentrations. Feeding supplements in a PMR reduced the incidence of ruminal acidosis and altered ruminal bacterial communities, regardless of supplement feeding amount, but did not result in increased milk measures compared with isoenergetic control diets component-fed to late-lactation cows.

Key words: bacterial community composition, partial mixed ration, protein, ruminal acidosis, supplements

\section{INTRODUCTION}

A TMR fed to cattle on a feed pad between grazing periods is termed a partial mixed ration (PMR) (Bargo 
et al., 2002b; Auldist et al., 2013). This feeding strategy increases milk yield and milk fat and protein percentage (Bargo et al., 2002a) and improves marginal milk responses and increased yields of milk fat (Auldist et al., 2013) over those of pasture-fed cows supplemented with grain in the milking parlor and conserved forage fed on the pasture.

Auldist et al. (2013) proposed that a well-formulated PMR that is consumed over a longer period could lead to more stable ruminal fermentation compared with grain fed in the parlor. The risk of ruminal acidosis may then be reduced, a hypothesis that is supported by a higher ruminal $\mathrm{pH}$ in PMR-fed compared with control cows fed grain in the parlor, silage, and freshcut pasture (Greenwood et al., 2014).

The substitution of some of the wheat for canola meal in a PMR also increased ECM and was associated with a higher concentration and yield of milk fat, and higher pasture DMI (Auldist et al., 2014). Other protein supplements, such as canola meal, have also increased milk yield (Oldham, 1984; Huhtanen et al., 2011; Martineau et al., 2013). Allen et al. (2006) proposed that high protein feeds have a buffering capacity in the rumen, which is consistent with the report of Auldist et al. (2014), in which substituting wheat for canola meal in a PMR decreased the amount of time $\mathrm{pH}$ was under 6.0 and increased mean daily ruminal $\mathrm{pH}$, despite having no significant influence on ruminal VFA (Auldist et al., 2014).

Understanding the complex and dynamic ruminal microbial ecosystem (Fernando et al., 2010) is essential to the development of feed management practices that promote optimal production efficiency (de Menezes et al., 2011). Ruminal acidosis is an important example of an interaction between ruminal microbial metabolism and diet that can impair health and production (Tajima et al., 2000; Khafipour et al., 2009). Weimer et al. (2010) suggested that the ruminal microbiome is reasonably resistant to dietary changes, and a change in the microbiome is not always related to the severity of ruminal acidosis (Mohammed et al., 2012). Early understandings of rumen microbiology and bacteria believed to be involved with ruminal acidosis were based on bacterial cultures. More recently, molecular techniques, which are rapidly improving and becoming less expensive, have been adopted in evaluations of rumen microbiology. Integration of knowledge obtained from classical culture-based microbiology and modern molecular techniques is rapidly increasing our understanding of the rumen microbiome and its functions in general (Pers-Kamczyc et al., 2011). This knowledge will potentially facilitate optimal dietary management and reduce the incidence of nutritional disorders such as ruminal acidosis, among other benefits. Despite constant evolution of methods for studying the rumen ecosystem, only about $10 \%$ of the rumen microbiome is known (Pers-Kamczyc et al., 2011). This limited knowledge impedes understanding of the importance of changes in ruminal microbial populations observed during rumen perturbation and ruminal acidosis.

Recent work suggests that the rumen has a core bacterial microbiome that consists primarily of bacteria from the Firmicutes and Bacteroidetes phyla, which appear to change in cattle fed various ruminal acidosis induction diets or increasing amounts of grain (Khafipour et al., 2009; Callaway et al., 2010; Fernando et al., 2010; de Menezes et al., 2011). Bacteria from the Proteobacteria appear to be the third most dominant in the rumen in several (Khafipour et al., 2009; Jami and Mizrahi, 2012), but not all, ruminant studies (Golder et al., 2014b). Increases in Proteobacteria have been reported in TMR-fed compared with pasture-fed cattle (de Menezes et al., 2011) and in cattle with graininduced compared with alfalfa pellet-induced subacute acidosis (Khafipour et al., 2009). Increases in Streptococcus and Lactobacillus were associated with ruminal acidosis in early work (Hungate et al., 1952; Hungate, 1966); however, as only a small portion of the rumen microbiome is known, other rumen bacteria may have prominent roles in acidosis.

The objectives of this study were to examine relationships between milk measures, ruminal fermentation measures, ruminal acidosis, and ruminal bacterial community composition (BCC) in lactating cows offered a restricted pasture allowance and fed supplements using different feeding strategies and at linearly increasing supplement amounts. The aim was to identify feed management systems that improve milk measures, promote optimal conditions in the rumen for digestion, and reduce ruminal acidosis.

The hypotheses tested were (1) that cows fed supplements as a PMR, with or without inclusion of canola meal, would have increased milk measures, altered ruminal measures, distinct ruminal BCC, and decreased ruminal acidosis compared with control cows fed isoenergetic diets as grain in the parlor and forage fed on the pasture; (2) that a linear increase in the amount of supplement fed (or increase when 14 and $16 \mathrm{~kg}$ of supplement DM are fed) would alter milk and ruminal fermentation measures, create a distinct ruminal BCC, and increase ruminal acidosis.

\section{MATERIALS AND METHODS}

The experiment was conducted in late fall at the Department of Environment and Primary Industries (DEPI), Ellinbank Centre, Victoria (VIC), Australia $\left(38^{\circ} 14^{\prime} \mathrm{S}, 145^{\circ} 56^{\prime} \mathrm{E}\right)$. All experimental procedures were 
approved by the DEPI Agricultural Research and Extension Animal Ethics Committee (AEC 2010-18).

\section{Experimental Design}

This prospective randomized controlled cohort experiment with an incomplete factorial design included 3 supplement feeding strategies and 5 supplementary feeding amounts offered to 144 Holstein-Friesian cows. These cows were seasonally calving, multiparous cows of mixed ages with an average liveweight of $625 \pm 45$ $\mathrm{kg}$ and were $272 \pm 17 \mathrm{DIM}$. Twenty-four of these cows were rumen fistulated. The cows were milked twice daily at approximately 0700 and $1500 \mathrm{~h}$. The experiment consisted of a 14-d pre-experimental period, during which cows were adapted to the amount of supplement, and a 16-d measurement period, during which DMI and milk production were measured. Ruminal fluid samples were collected on $\mathrm{d} 7$ of the measurement period.

\section{Supplement Feeding Strategies}

All 144 cows had been fed either a control or PMR diet before the experiment and were randomized into 24 groups; each group of 6 cows was an experimental unit. Each group was allocated to one of the following feeding strategies:

(1) In the control strategy (10 groups), cows grazed a perennial ryegrass (Lolium perenne L.) pasture supplemented with crushed wheat grain individually hand-fed twice daily in the milking parlor and ryegrass silage fed under an electric wire on the pasture. The ratio of ryegrass silage:wheat grain fed as supplement was 27:73 (DM basis). The pasture allowance was kept constant at 15 $\mathrm{kg}$ of DM/cow per day measured to ground level, to provide a target intake of approximately $8 \mathrm{~kg}$ of $\mathrm{DM} /$ cow per day.

(2) In the PMR strategy (10 groups), cows grazed perennial ryegrass pasture twice daily at the same allowance as the control cows, were fed approximately $45 \%$ of their daily allocation of crushed wheat in the milking parlor, and were fed a PMR in equal proportions on a concrete feed pad immediately after each milking. The PMR comprised crushed wheat grain, crushed maize grain, maize silage, and ryegrass silage mixed and chopped in a feed wagon (model K160, Richard Keenan and Co. Ltd., Co. Carlow, Ireland; Table 1). Water was added to the ration such that the final DM content of the ration ap- proximated $50 \%$. The PMR provided the same estimated ME intake as the supplements fed to the control cows and had the same ratio of forage to grain, but was formulated to ferment more slowly.

(3) In the PMR+canola strategy (4 groups), cows were fed and managed the same as the PMR cows, except that the ration contained alfalfa hay instead of ryegrass silage and 16\% DM of the crushed wheat grain was replaced with solvent-extracted canola meal (Table 1). This ration provided the same $\mathrm{ME}$ as the control and PMR diets but had estimated amounts of MP that exceeded requirements (NRC, 2001).

\section{Amount of Supplement}

Each group of 6 cows was randomly assigned within their feeding strategy to receive different amounts of supplement, and each group contained a rumen-fistulated cow ( $\mathrm{n}=2$ fistulated cows/feeding strategy per supplement feeding amount; Table 1). For the control and PMR cows, 2 groups were assigned to receive 8 , $10,12,14$, or $16 \mathrm{~kg}$ of total supplement $\mathrm{DM} /$ cow per day (SDM). For the PMR+canola cows, 2 groups were assigned to receive either 14 or $16 \mathrm{~kg}$ of SDM. Cows fed the 14 and $16 \mathrm{~kg}$ of SDM amounts were introduced gradually to dietary regimens over the first $7 \mathrm{~d}$ of the pre-experimental period.

As part of their supplement, all cows received a vitamin and mineral pellet (Nutrifeed Hi-Milker, Debenham Australia Pty Ltd., Leongatha, VIC, Australia) that contained monensin $(110 \mathrm{mg} / 100 \mathrm{~g}$ of pellets $)$ and tylosin $(110 \mathrm{mg} / 100 \mathrm{~g}$ of pellets; Table 1$)$. Cows at the highest amount of supplementation (16 kg of SDM) received this supplement at the amount recommended by the manufacturers (250 g of pellets/cow per day), whereas cows receiving lower amounts of supplement received proportionally less (e.g., cows fed $8 \mathrm{~kg}$ of SDM received $125 \mathrm{~g} /$ cow per day of the vitamin and mineral pellet). Control cows received their vitamin and mineral pellets mixed with their grain at milking time, whereas cows fed PMR and PMR+canola received their pellets mixed into their PMR.

All cows remained in their groups of 6 during feeding and grazing and had several opportunities each day to access water ad libitum. Control cows had access to pasture immediately after each milking, whereas those fed the PMR and PMR+canola diets had access after they had consumed their ration on the feed pad. Each group of 6 cows grazed adjacent areas separated by electric tapes and were prevented from regrazing areas from the previous days. 
Table 1. Target DMI of ration composition ( $\mathrm{kg}$ of total supplement DM/cow per day) and actual DMI of feeding groups

\begin{tabular}{|c|c|c|c|c|c|c|c|c|c|c|c|c|}
\hline \multirow[b]{3}{*}{ Ration component } & \multicolumn{12}{|c|}{ Feeding strategy and supplement feeding amount ${ }^{1}$ ( $\mathrm{kg}$ of total supplement DM/cow per day) } \\
\hline & \multicolumn{5}{|c|}{ Control } & \multicolumn{5}{|c|}{ PMR } & \multicolumn{2}{|c|}{ PMR+canola } \\
\hline & 8 & 10 & 12 & 14 & 16 & 8 & 10 & 12 & 14 & 16 & 14 & 16 \\
\hline \multicolumn{13}{|l|}{ Target DMI } \\
\hline Crushed wheat ${ }^{2}$ & 5.8 & 7.3 & 8.8 & 10.4 & 11.7 & 3.0 & 3.8 & 4.6 & 5.4 & 6.2 & 3.1 & 3.5 \\
\hline Crushed maize & - & - & - & - & - & 1.6 & 2.0 & 2.4 & 2.8 & 3.2 & 2.8 & 3.2 \\
\hline Alfalfa hay & - & - & - & - & - & 1.0 & 1.2 & 1.4 & 1.6 & 1.8 & 1.7 & 1.9 \\
\hline Maize silage & - & - & - & - & - & 2.4 & 3.0 & 3.6 & 4.2 & 4.8 & 4.2 & 4.8 \\
\hline Canola meal & - & - & - & - & - & - & - & - & - & - & 2.2 & 2.6 \\
\hline Ryegrass silage & 2.2 & 2.7 & 3.2 & 3.6 & 4.3 & - & - & - & - & - & - & - \\
\hline $\begin{array}{l}\text { Pasture } \\
\text { Pasto }\end{array}$ & 8.0 & 8.0 & 8.0 & 8.0 & 8.0 & 8.0 & 8.0 & 8.0 & 8.0 & 8.0 & 8.0 & 8.0 \\
\hline Total & 16.0 & 18.0 & 20.0 & 22.0 & 24.0 & 16.0 & 18.0 & 20.0 & 22.0 & 24.0 & 22.0 & 24.0 \\
\hline \multicolumn{13}{|l|}{ Actual DMI } \\
\hline Crushed wheat & $5.3 \pm 0.0$ & $6.6 \pm 0.0$ & $7.7 \pm 0.0$ & $8.8 \pm 0.2$ & $10.0 \pm 0.3$ & $1.4 \pm 0.0$ & $1.8 \pm 0.1$ & $2.0 \pm 0.1$ & $2.2 \pm 0.0$ & $2.6 \pm 0.0$ & $2.3 \pm 0.0$ & $2.6 \pm 0.0$ \\
\hline Ryegrass silage & $2.5 \pm 0.0$ & $3.1 \pm 0.0$ & $3.8 \pm 0.0$ & $4.4 \pm 0.0$ & $5.0 \pm 0.0$ & - & - & - & - & - & - & - \\
\hline PMR & - & - & - & - & - & $7.1 \pm 0.2$ & $9.2 \pm 0.3$ & $11.1 \pm 0.1$ & $12.9 \pm 0.1$ & $14.6 \pm 0.1$ & $13.2 \pm 0.0$ & $14.9 \pm 0.0$ \\
\hline Pasture & $8.8 \pm 0.0$ & $9.1 \pm 0.3$ & $8.3 \pm 0.5$ & $9.0 \pm 0.0$ & $7.9 \pm 0.2$ & $8.6 \pm 0.4$ & $8.7 \pm 0.6$ & $7.9 \pm 0.5$ & $8.0 \pm 0.0$ & $7.8 \pm 0.1$ & $8.2 \pm 0.3$ & $8.0 \pm 0.1$ \\
\hline Total supplement & $7.8 \pm 0.0$ & $9.8 \pm 0.0$ & $11.4 \pm 0.0$ & $13.2 \pm 0.2$ & $15.1 \pm 0.3$ & $8.4 \pm 0.2$ & $11.0 \pm 0.1$ & $13.1 \pm 0.0$ & $15.2 \pm 0.1$ & $17.2 \pm 0.1$ & $15.5 \pm 0.0$ & $17.5 \pm 0.1$ \\
\hline Total & $16.6 \pm 0.0$ & $18.9 \pm 0.3$ & $19.7 \pm 0.5$ & $22.2 \pm 0.2$ & $23.0 \pm 0.5$ & $17.1 \pm 0.5$ & $19.8 \pm 0.7$ & $21.0 \pm 0.5$ & $23.1 \pm 0.1$ & $25.0 \pm 0.0$ & $23.8 \pm 0.2$ & $25.5 \pm 0.0$ \\
\hline
\end{tabular}

${ }^{1}$ PMR = partial mixed ration; PMR +canola = PMR + canola meal. Rations also contained a vitamin and mineral mix (Nutrifeed Hi-Milker pellets; Debenham Australia Pty Ltd., Leongatha, Victoria, Australia) that contained (110 mg/100 g pellets) of monensin and (110 mg/100 g pellets) of tylosin. Cows at the highest amount of supplementation (16 kg of DM/cow per day) received this supplement at the amount recommended by the manufacturers (125 g pellet/cow per day), whereas cows receiving lower amounts of supplement received proportionally less (e.g., cows fed $8 \mathrm{~kg}$ of DM supplement/d received $71 \mathrm{~g} / \mathrm{cow}$ per day of the vitamin and mineral pellet).

${ }^{2}$ Approximately $45 \%$ of the target DMI for crushed wheat for the PMR-fed cows was offered in the milking parlor and the remainder was included in the PMR 


\section{Nutritive Characteristics and Supplement and Pasture Intakes}

All ration components were analyzed by near-infrared spectroscopy (method 989.03; AOAC International, 2000; Dairy One Inc., Forage Testing Laboratory, Ithaca, NY; Table 2), and ration chemical composition was estimated in CPM Dairy Ration Analyzer V3.10 (Cornell-Penn-Miner, Cornell University, Ithaca, NY; Table 3). Rations offered and refused were weighed every day of the measurement period and subsamples of ration residuals were collected and analyzed for DM and nutritive characteristics to allow the calculation of daily DMI and estimated ME intake for each group.

Pre- and postgrazing mass was measured daily (Pasturemeter XP1, C-Daz Ltd., Palmerston North, New Zealand) to calculate average pasture DMI for each group. Pre- and postgrazing pasture samples were collected from each new pasture break grazed by cutting pasture at ground level using electric shears. Samples were washed, freeze-dried, and ground through a 0.5$\mathrm{mm}$ sieve, and DM digestibility was analyzed by nearinfrared spectroscopy (Dairy One Inc.) to estimate ME.

\section{Milk Sampling Procedure and Laboratory Analysis}

Milk yield of every cow was measured at each milking during both the pre-experimental and measurement periods using the DeLaval Alpro milk metering system (DeLaval International AB, Tumba, Sweden). Fat and protein concentrations of the daily milk from each cow were determined twice a week during both periods using inline milk meters (DeLaval International AB) and an infrared milk analyzer (model 2000; Bentley Instruments Inc., Chaska, MN).

\section{Ruminal Fluid Sampling Procedure}

On d 7 of the measurement period, ruminal fluid was collected from each rumen-fistulated cow (2 cows per feeding group) at approximately 2.4-h intervals over a 24-h period, totaling 10 samples per cow. This was done by restraining the cows in temporary yards set up in the pasture or in permanent yards next to the feed pad and milking parlor. The first sample was collected after the morning milking at approximately $0820 \mathrm{~h}$. Samples were collected per fistula using a $100-\mathrm{mL}$ plastic syringe connected to a brass pipe inserted into the rumen. Fluid was collected from several sites within the rumen and immediately tested for $\mathrm{pH}$ (Hannah HI9023 pH meter, Hannah Instruments, Keysborough, VIC, Australia). An additional untreated sample was stored at $-20^{\circ} \mathrm{C}$ for ruminal bacterial analysis. Ruminal data from sample time 8 were excluded from the data set due to sampling error.

\section{Ruminal Fluid Laboratory Analysis}

For VFA analysis, an aliquot of $4 \mathrm{~mL}$ of ruminal fluid was dispensed into a tube containing $1 \mathrm{~mL}$ of $25 \%$ metaphosphoric acid before being stored at $-20^{\circ} \mathrm{C}$ until subsequent analysis by capillary gas chromatography using the method of Packer et al. (2011).

For ammonia analysis, an aliquot of $10 \mathrm{~mL}$ of ruminal fluid was dispensed into a tube containing $10 \mathrm{~mL}$ of $0.1 \mathrm{M} \mathrm{HCl}$ before being stored at $-20^{\circ} \mathrm{C}$ until analysis. Concentrations of ammonia were assayed by a direct enzymatic procedure using a commercially available kit (Boehringer Mannheim; R-Biopharm Laboratory Diagnostics Pty Ltd., Taren Point, NSW, Australia) and a Cobas Mira S autoanalyzer (Roche, Montclair, NJ).

D-Lactate was analyzed using a UV method for D-lactate determination in ruminal fluid using a Boehringer

Table 2. Chemical composition of feed components and pasture ${ }^{1}$

\begin{tabular}{lrcccccc}
\hline & \multicolumn{7}{c}{ Feed component } \\
\cline { 2 - 7 } Item & $\begin{array}{c}\text { Crushed } \\
\text { wheat }\end{array}$ & $\begin{array}{c}\text { Crushed } \\
\text { maize }\end{array}$ & $\begin{array}{c}\text { Alfalfa } \\
\text { hay }\end{array}$ & $\begin{array}{c}\text { Maize } \\
\text { silage }\end{array}$ & $\begin{array}{c}\text { Canola } \\
\text { meal }\end{array}$ & $\begin{array}{c}\text { Ryegrass } \\
\text { silage }\end{array}$ & $\begin{array}{c}\text { Pasture } \\
\text { consumed }\end{array}$ \\
\hline CP & 13.8 & 10.0 & 18.6 & 10.0 & 37.4 & 13.3 & 22.2 \\
ADF & 5.3 & 4.5 & 36.3 & 25.7 & 21.9 & 40.1 & 27.5 \\
NDF & 12.9 & 13.3 & 44.9 & 46.0 & 30.2 & 61.3 & 49.9 \\
Lignin & 0.7 & 0.6 & 10.9 & 3.3 & 10.5 & 3.7 & 3.4 \\
NFC & 74.4 & 70.8 & 28.0 & 36.8 & 25.5 & 14.8 & 17.1 \\
Starch & 54.2 & 59.8 & 2.6 & 28.4 & 1.2 & 0.7 & 1.5 \\
Crude fiber & 2.0 & 5.5 & 2.1 & 4.0 & 6.6 & 3.9 & 5.8 \\
Ash & 1.7 & 1.9 & 11.3 & 4.9 & 8.9 & 9.0 & 10.0 \\
ME (MJ/kg of DM) & 14.7 & 14.6 & 8.2 & 10.8 & 12.7 & 9.7 & 11.5 \\
\hline
\end{tabular}

${ }^{1}$ Analyzed by near-infrared spectroscopy (Dairy One Inc., Forage Testing Laboratory, Ithaca, NY). 
Table 3. Predicted chemical composition of consumed rations

\begin{tabular}{|c|c|c|c|c|c|c|c|c|c|c|c|c|}
\hline \multirow[b]{3}{*}{ Item $(\%$ of $\mathrm{DM})$} & \multicolumn{12}{|c|}{ Feeding strategy and supplement feeding amount ${ }^{2}$ (kg of total supplement DM/cow per day) } \\
\hline & \multicolumn{5}{|c|}{ Control } & \multicolumn{5}{|c|}{ PMR } & \multicolumn{2}{|c|}{$\mathrm{PMR}+$ canola } \\
\hline & 8 & 10 & 12 & 14 & 16 & 8 & 10 & 12 & 14 & 16 & 14 & 16 \\
\hline $\mathrm{DM}$ & 77.6 & 76.5 & 74.9 & 74.5 & 72.6 & 75.9 & 73.9 & 71.4 & 70.1 & 68.6 & 70.2 & 68.6 \\
\hline $\mathrm{CP}$ & 18.1 & 17.7 & 17.1 & 17.0 & 16.5 & 17.4 & 16.7 & 16.0 & 15.7 & 15.4 & 18.2 & 18.1 \\
\hline RUP (\% of CP) & 26.9 & 27.7 & 27.6 & 28.8 & 28.5 & 27.5 & 28.7 & 29.1 & 30.1 & 30.9 & 35.2 & 34.6 \\
\hline RDP (\% of CP) & 73.1 & 72.3 & 72.4 & 71.2 & 71.5 & 72.5 & 71.3 & 71.0 & 69.9 & 69.1 & 64.8 & 65.4 \\
\hline $\mathrm{RDP}$ & 13.2 & 12.8 & 12.4 & 12.1 & 11.8 & 12.6 & 11.9 & 11.4 & 11.0 & 10.7 & 11.8 & 11.8 \\
\hline Soluble protein (\% of CP) & 35.7 & 36.1 & 36.9 & 37.1 & 37.8 & 35.2 & 35.7 & 36.2 & 36.5 & 36.8 & 35.1 & 35.2 \\
\hline $\mathrm{ADF}$ & 22.2 & 21.6 & 21.1 & 21.0 & 20.4 & 21.4 & 20.5 & 19.6 & 19.2 & 18.7 & 21.0 & 20.7 \\
\hline NDF & 39.6 & 38.6 & 37.4 & 37.2 & 36.0 & 38.5 & 37.0 & 35.4 & 34.6 & 33.8 & 36.5 & 35.9 \\
\hline Forage NDF ( $\%$ of NDF) & 89.5 & 88.1 & 86.5 & 86.1 & 84.2 & 65.5 & 59.6 & 53.1 & 49.8 & 46.1 & 81.7 & 43.6 \\
\hline Forage NDF ( $\%$ of DM) & 35.4 & 34.0 & 32.4 & 32.1 & 30.3 & 25.2 & 22.0 & 18.8 & 17.2 & 15.6 & 29.9 & 15.7 \\
\hline Physically effective NDF & 27.8 & 27.1 & 26.4 & 26.3 & 25.4 & 27.7 & 26.7 & 25.7 & 25.1 & 15.6 & 26.0 & 25.6 \\
\hline Lignin & 2.57 & 2.48 & 2.39 & 2.37 & 2.27 & 3.07 & 3.00 & 2.93 & 2.89 & 2.85 & 3.80 & 3.83 \\
\hline $\mathrm{NFC}^{3}$ & 33.4 & 35.1 & 37.0 & 37.4 & 39.5 & 35.3 & 37.8 & 40.4 & 41.7 & 43.0 & 36.8 & 37.7 \\
\hline Silage acids & 0.10 & 0.10 & 0.12 & 0.13 & 0.14 & 0.74 & 0.84 & 0.94 & 0.98 & 1.03 & 0.98 & 1.03 \\
\hline Sugar & 9.86 & 9.44 & 8.85 & 8.73 & 8.18 & 9.23 & 8.58 & 7.92 & 7.60 & 7.26 & 8.28 & 8.01 \\
\hline Starch & 17.6 & 19.3 & 21.3 & 21.7 & 23.8 & 20.2 & 22.9 & 25.6 & 27.0 & 28.4 & 21.3 & 22.2 \\
\hline Soluble fiber & 5.89 & 6.26 & 6.74 & 6.84 & 7.31 & 5.15 & 5.52 & 5.90 & 6.08 & 6.27 & 6.28 & 6.47 \\
\hline Total ether extract & 4.29 & 4.14 & 3.94 & 3.90 & 3.71 & 4.57 & 4.42 & 4.25 & 4.17 & 4.09 & 4.65 & 4.61 \\
\hline Total long-chain FA & 2.71 & 2.63 & 2.52 & 2.50 & 2.40 & 3.11 & 3.06 & 3.00 & 2.98 & 2.95 & 3.33 & 3.34 \\
\hline Ash & 7.55 & 7.34 & 7.05 & 7.00 & 6.70 & 7.39 & 7.06 & 6.68 & 6.50 & 6.31 & 7.29 & 7.16 \\
\hline DCAD (mEq/100 g) & 50.1 & 45.8 & 40.0 & 38.7 & 33.2 & 51.3 & 45.7 & 40.0 & 37.3 & 34.4 & 37.5 & 34.6 \\
\hline \multicolumn{13}{|l|}{ Minerals $(\mathrm{mg} / \mathrm{kg})$} \\
\hline Chloride & 6,800 & 6,900 & 7,200 & 7,300 & 7,400 & 4,200 & 4,100 & 3,900 & 3,800 & 3,700 & 3,700 & 3,600 \\
\hline Calcium & 4,600 & 4.800 & 5,000 & 5,100 & 5,200 & 4,100 & 4,200 & 4,200 & 4,200 & 4,200 & 5,000 & 5,100 \\
\hline Copper & 9.38 & 9.68 & 9.88 & 9.95 & 10.1 & 9.78 & 10.2 & 10.4 & 10.5 & 10.6 & 10.4 & 10.5 \\
\hline Iron & 154 & 155 & 156 & 157 & 157 & 157 & 158 & 158 & 157 & 157 & 182 & 183 \\
\hline Phosphorus & 5,500 & 5,400 & 5,200 & 5,200 & 5,000 & 5,200 & 5,000 & 4,800 & 4,700 & 4,600 & 5,600 & 5,500 \\
\hline Potassium & 30,300 & 28,400 & 25,900 & 25,400 & 23,000 & 29,300 & 26,600 & 23,900 & 22,600 & 21,300 & 23,700 & 22,500 \\
\hline Magnesium & 2,100 & 2,200 & 2,200 & 2,200 & 2,200 & 2,200 & 2,200 & 2,200 & 2,300 & 2,300 & 2,600 & 2,700 \\
\hline Manganese & 46.5 & 46.4 & 45.8 & 45.7 & 45.3 & 43.2 & 42.7 & 41.8 & 41.4 & 41.0 & 43.8 & 43.6 \\
\hline Sodium & 2,000 & 2,000 & 2,200 & 2,200 & 2,300 & 1,000 & 1,000 & 1,000 & 900 & 900 & 1,000 & 1,000 \\
\hline Sulfur & 2,700 & 2,600 & 2,500 & 2,500 & 2,400 & 2,600 & 2,400 & 2,300 & 2,300 & 2,200 & 2,700 & 2,700 \\
\hline Zinc & 44.7 & 45.7 & 46.3 & 46.5 & 47.1 & 41.8 & 42.6 & 42.8 & 42.9 & 43.0 & 44.9 & 45.2 \\
\hline
\end{tabular}

${ }^{1}$ Estimations were performed using CPM Dairy Analyzer V3.10 (Cornell-Penn-Miner, Cornell University, Ithaca, NY) using DMI data from Table 1 and chemical composition of feed ration components in Table 2 and were based on 625-kg BW cows, 272 DIM, with a BCS of 3.00 and mean milk yield, milk fat and protein percentage for each group. ${ }^{2} \mathrm{PMR}=$ partial mixed ration; $\mathrm{PMR}+$ canola $=\mathrm{PMR}+$ canola meal

${ }^{3} \mathrm{NFC}=100-[(\mathrm{NDF}-\mathrm{NDICP})+\mathrm{CP}+$ crude fat + ash $]$, where NDICP $=$ neutral detergent insoluble $\mathrm{CP}$ 
Mannheim kit (cat no. 11112821 035; R-BiopharmLaboratory Diagnostics Pty. Ltd.) after deproteinization with perchloric acid according to kit instructions on an Olympus AU400 Autoanalyzer (AHL NTM-56; Olympus, Mount Waverly, VIC, Australia).

\section{DNA Extraction}

Bacterial community composition was determined on unfiltered ruminal fluid that was primarily liquid but contained particulate matter, thus representing a mixture of the liquid and particulate phases of the rumen, that was collected at approximately 0820, 1200, and $1640 \mathrm{~h}$ (sampling times 1, 3, and 5) on d 7 of the measurement period. Ruminal fluid samples $(\mathrm{n}=72)$ were thawed at room temperature and a 1-mL aliquot was centrifuged at $10,000 \times g$ for $1 \mathrm{~min}$ and the supernatant discarded. The pellet was resuspended by vigorous vortexing in $200 \mu \mathrm{L}$ of ATL buffer (Qiagen GmbH, Hilden, Germany) together with $200 \mathrm{mg}$ of silica-zirconium beads (1:1 mixture of 0.1- and 1.0-mm beads; Biospec, Bartlesville, OK). The mixture was homogenized in a FastPrep-24 homogenizer (MP Biomedicals, Seven Hills, New South Wales, Australia) at maximum speed for $1 \mathrm{~min}$, twice, heated at $70^{\circ} \mathrm{C}$ for $15 \mathrm{~min}$, and centrifuged at $10,000 \times g$ for $5 \mathrm{~min}$. Supernatant $(180 \mu \mathrm{L})$ was removed for digestion with proteinase $\mathrm{K}$ at $50^{\circ} \mathrm{C}$ for at least $3 \mathrm{~h}$, and DNA was extracted according to the QIAmp DNA mini kit protocol (Qiagen $\mathrm{GmbH}$ ). DNA was quantified using a Nanodrop spectrophotometer ND-1000 (Thermo Scientific, Waltham, MA).

\section{PCR Amplification of 16S Ribosomal DNA Gene Sequences}

Genomic DNA from each sample was diluted 1:30 with water and the $16 \mathrm{~S}$ rRNA gene spanning V1 to V3 was PCR amplified using Platinum Taq polymerase (Invitrogen, Carlsbad, CA) as follows: 1 cycle at $94^{\circ} \mathrm{C}$ for $2 \mathrm{~min}$, followed by 30 cycles of $94^{\circ} \mathrm{C}$ for $10 \mathrm{~s}, 55^{\circ} \mathrm{C}$ for $45 \mathrm{~s}, 72^{\circ} \mathrm{C}$ for $45 \mathrm{~s}$, with a final extension of $72^{\circ} \mathrm{C}$ for $10 \mathrm{~min}$. Primers used in the reaction were modified universal 8F (Snell-Castro et al., 2005) and 515R (Lane, 1991) primers that included 454 sequencing adapters $B$ and $\mathrm{A}$, respectively. In addition, a unique 8-bp barcode was included in the reverse primer of each amplicon, so that DNA sequence reads could be assigned accurately to each originating sample. The PCR products were visualized on agarose gels and equal amounts of PCR product were pooled and gel extracted (Qiaex gel extraction kit, Qiagen). Approximately $3 \mu \mathrm{g}$ of pooled amplicon $(\sim 40 \mathrm{ng} / \mu \mathrm{L})$ was dispatched to Macrogen (Seoul, Korea) for 454 DNA sequencing using a 454
GS FLX Sequencer with titanium chemistry (Roche, Branford, CT).

\section{Sequence Analyses of Gene Amplicons}

Sequence data was processed using the quantitative insights into microbial ecology software package QIIME (Caporaso et al., 2010). Sequences were assigned to their originating sample based on the attached barcode and filtered based on quality and length parameters. Error correction of 454 data was performed using Acacia (Bragg et al., 2012). Clustering of sequences to an operational taxonomic unit (OTU) at a 0.97 distance threshold was used. Taxonomic identification was based on similarity to the Greengenes Database (http:// greengenes.lbl.gov). The OTU table was subjected to $\alpha$ and $\beta$ diversity measures using QIIME and passed through R (package Ade4; Dray and Dufour, 2007) for nonconstrained principal coordinates and constrained principal coordinates between group analysis, Monte Carlo tests, and co-inertia analysis.

\section{Statistical Analysis}

DMI. Dry matter intake data (Table 4) were derived by averaging daily group measures over the measurement period, and data from all feeding amounts $(\mathrm{n}=$ 144 cows) were analyzed using a linear mixed model in Genstat (14th ed., VSN International Ltd., Hemel Hempstead, UK), using model [1], with the modification of removal of time and interactions with time from the model. Orthogonal polynomial linear and quadratic contrasts were included for feeding amount. The correlation structure of the random error terms was independent:

$$
\begin{aligned}
& \mathrm{Y}_{\mathrm{ijklmn}}=\mu+\alpha_{\mathrm{i}}+\beta_{\mathrm{j}}+(\alpha \beta)_{\mathrm{ij}}+(\alpha \gamma)_{\mathrm{ik}}+(\alpha \delta)_{\mathrm{il}} \\
& +(\alpha \gamma \delta)_{\mathrm{ikl}}+(\beta \gamma)_{\mathrm{jk}}+(\beta \delta)_{\mathrm{jl}}+(\beta \gamma \delta)_{\mathrm{jkl}}+(\alpha \beta \gamma)_{\mathrm{ijk}} \\
& +(\alpha \beta \delta)_{\mathrm{ijl}}+(\alpha \beta \gamma \delta)_{\mathrm{ijkl}}+\mathrm{X}_{\mathrm{m}}+(\mathrm{XY})_{\mathrm{mn}}+\varepsilon_{\mathrm{ijk} \mathrm{mn}},
\end{aligned}
$$

where $Y_{\mathrm{ijklmn}}=$ response at time $\mathrm{i}(\mathrm{i}=1$ to 9 , or 1 to 3 ), to protein $\mathrm{j}$ (yes or no), for feeding strategy $\mathrm{k}(\mathrm{k}=$ 1 or 2 ), at supplement feeding amount $\mathrm{l}(\mathrm{l}=1$ to 5$)$, for herd $\mathrm{m}(\mathrm{m}=1$ to 5$)$, in group $\mathrm{n}(\mathrm{n}=1$ to 5$) ; \mu=$ overall mean; $\alpha=$ time; $\beta=$ protein; $\gamma=$ feeding strategy nested within time and protein; $\delta=$ supplement feeding amount nested within time and protein; $\mathrm{X}=$ herd; $\mathrm{Y}=$ group nested within herd; and $\varepsilon=$ random error.

To incorporate the effect of protein, data from the groups fed total supplement at amounts of 14 and $16 \mathrm{~kg}$ of $\mathrm{DM} /$ cow per day were termed the high supplement feeding amounts and were analyzed using model [2], 
Table 4. Main effects and interaction of feeding strategy (S) and supplement feeding amount (A), and means \pm SE of the difference (SED) of feeding strategy for DMI, milk yield, and milk composition of the herd including fistulates $(\mathrm{n}=144$ cows)

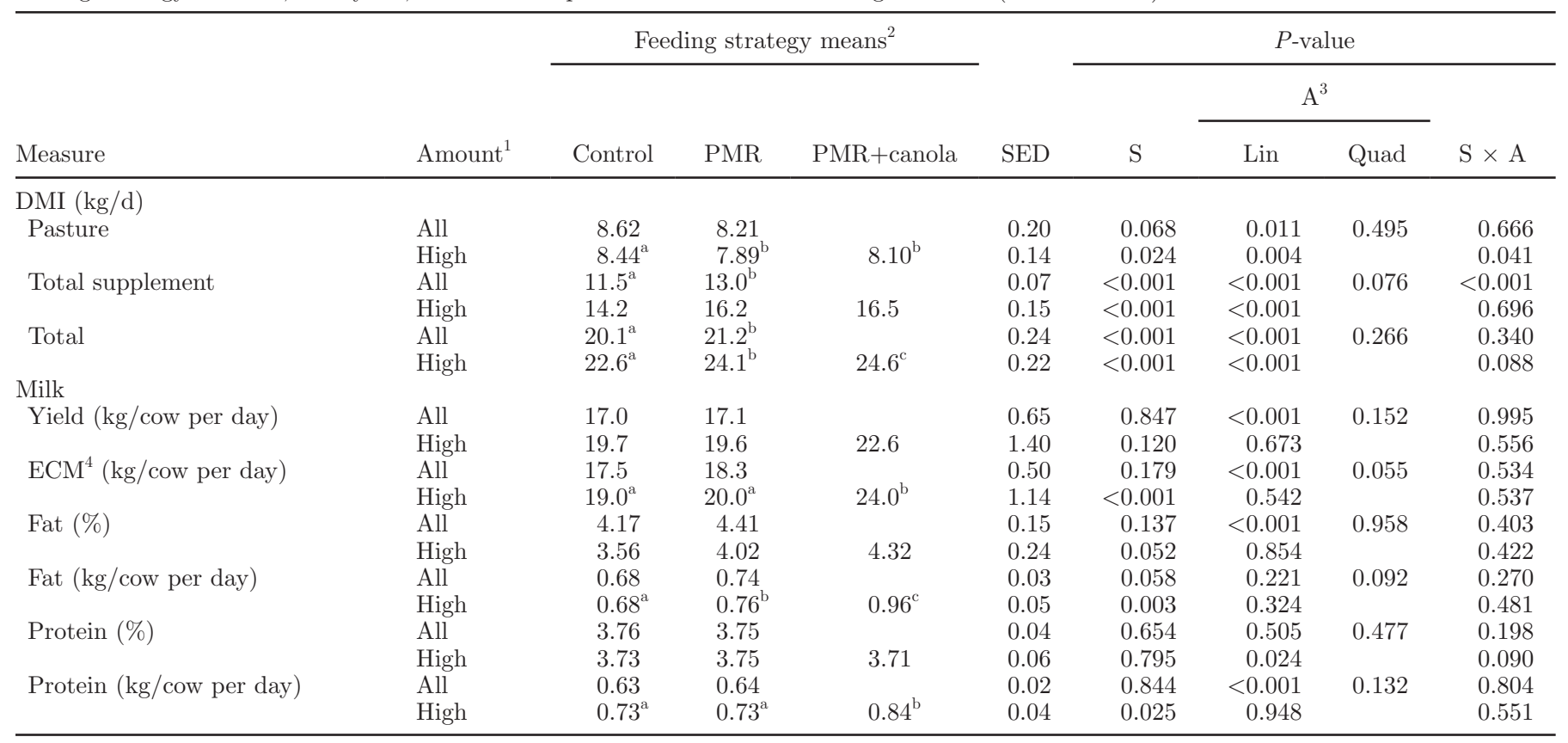

${ }^{\mathrm{a}-\mathrm{c}}$ Means within a row not sharing a common superscript differ significantly $(P<0.05)$.

${ }^{1}$ All $=$ supplement feeding amounts $8,10,12,14$, and $16 \mathrm{~kg}$ of DM total supplement/cow per day; High = supplement feeding amounts 14 and $16 \mathrm{~kg}$ of DM total supplement/cow per day, to incorporate the effect of canola meal substitution.

${ }^{2} \mathrm{PMR}=$ partial mixed ration; PMR + canola $=\mathrm{PMR}+$ canola meal.

${ }^{3} \mathrm{Lin}=$ linear polynomial contrast; Quad = quadratic polynomial contrast.

${ }^{4}$ Standardized to $4.0 \%$ fat and $3.3 \%$ protein, was calculated using the following formula: $\mathrm{ECM}(\mathrm{kg} / \mathrm{cow}$ per day $)=$ milk yield $\mathrm{kg} \times(376 \times$ fat $\%+209 \times$ protein $\%+948) / 3,138$ (Tyrrell and Reid, 1965)

with the modification of removal of time and interactions with time from the model. Orthogonal polynomial linear and quadratic contrasts were not included in this analysis as the high supplement feeding amounts comprised only 2 feeding amounts. The correlation structure of the random error terms was independent:

$$
\begin{aligned}
\mathrm{Y}_{\mathrm{ijklm}}= & \mu+\alpha_{\mathrm{i}}+\gamma_{\mathrm{j}}+\delta_{\mathrm{k}}+(\gamma \delta)_{\mathrm{jk}}+(\alpha \gamma)_{\mathrm{ij}}+(\alpha \delta)_{\mathrm{ik}} \\
& +(\alpha \gamma \delta)_{\mathrm{iik}}+\mathrm{X}_{\mathrm{m}}+(\mathrm{XY})_{\mathrm{mn}}+\varepsilon_{\mathrm{ijklm}}
\end{aligned}
$$

where $\mathrm{Y}_{\mathrm{ijklm}}=$ response at time $\mathrm{i}(\mathrm{i}=1$ to 9$)$, for feeding strategy $\mathrm{j}(\mathrm{j}=1$ to 3 ), at supplement feeding amount $\mathrm{k}$ $(\mathrm{k}=1$ to 5$)$, for herd $\mathrm{l}(\mathrm{l}=1$ to 5$)$, in group $\mathrm{m}(\mathrm{m}=1$ to 5$) ; \mu=$ overall mean; $\alpha=$ time; $\gamma=$ feeding strategy; $\delta=$ supplement feeding amount; $\mathrm{X}=$ herd; $\mathrm{Y}=$ group nested within herd; and $\varepsilon=$ random error.

Milk Measures. Milk measures (Table 4) were derived by averaging daily individual measures over the measurement period and were analyzed for the herd ( $\mathrm{n}=144$ cows $)$ and for the fistulates only $(\mathrm{n}=24$ cows) for all supplement feeding amounts and the high supplement feeding amounts, using models [1] and [2], respectively, with the removal of time and interactions with time from each model. Orthogonal polynomial linear and quadratic contrasts were included for supplement feeding amount in model [1].

Ruminal Measures. Ruminal data (Table 5) from 9 sampling times from the fistulated cattle were analyzed for all supplement feeding groups ( $\mathrm{n}$ of samples $=216$ ) and the high supplement feeding amount groups (n of samples $=108$ ) using models [1] and [2], respectively. Orthogonal polynomial linear and quadratic contrasts were included for feeding amount in model [1].

Bacterial Prevalence. The relative abundance of bacterial families in ruminal fluid collected at approximately 0820, 1200, and $1640 \mathrm{~h}$ (sampling times 1, 3, and 5) with a mean relative abundance of $>0.2 \%$ for at least one feeding strategy were analyzed for all supplement feeding amounts ( $\mathrm{n}$ of samples $=72$ ) and the high supplement feeding amounts ( $\mathrm{n}$ of samples $=36$ ) using the same linear mixed models used for the ruminal data. The relative abundances of the following bacterial genera were also analyzed using the same models: Prevotella, Lactobacillus, Butyrivibrio, Megasphaera, Selenomonas, Veillonella, and Streptococcus.

Evaluation of Ruminal Acidosis. The incidence of ruminal acidosis was diagnosed using eigenvalues 
Table 5. Main effects and their interactions of feeding strategy (S), supplement feeding amount (A), and sample time (T) and means \pm SE of the difference (SED) of feeding strategy for acidosis eigenvalues and ruminal measures

\begin{tabular}{|c|c|c|c|c|c|c|c|c|c|c|c|c|c|}
\hline \multirow[b]{3}{*}{ Item } & \multirow[b]{3}{*}{ Amount $^{1}$} & \multicolumn{3}{|c|}{ Feeding strategy means ${ }^{2}$} & \multirow[b]{3}{*}{ SED } & \multicolumn{8}{|c|}{$P$-value } \\
\hline & & \multirow[b]{2}{*}{ Control } & \multirow[b]{2}{*}{ PMR } & \multirow[b]{2}{*}{ PMR+canola } & & \multirow[b]{2}{*}{ S } & \multicolumn{2}{|c|}{$\mathrm{A}^{3}$} & \multirow[b]{2}{*}{$\mathrm{T}$} & \multirow[b]{2}{*}{$\mathrm{S} \times \mathrm{A}$} & \multirow[b]{2}{*}{$\mathrm{S} \times \mathrm{T}$} & \multirow[b]{2}{*}{$\mathrm{A} \times \mathrm{T}$} & \multirow[b]{2}{*}{$\mathrm{S} \times \mathrm{A} \times \mathrm{T}$} \\
\hline & & & & & & & Lin & Quad & & & & & \\
\hline Acidosis eigenvalue & All & $0.26^{\mathrm{a}}$ & $0.06^{\mathrm{b}}$ & & 0.07 & 0.012 & $<0.001$ & 0.014 & $<0.001$ & 0.075 & 0.030 & $<0.001$ & 0.154 \\
\hline & High & 0.63 & 0.14 & 0.06 & 0.16 & 0.066 & 0.104 & & $<0.001$ & 0.654 & 0.027 & 0.259 & 0.393 \\
\hline \multicolumn{14}{|l|}{ Ruminal (mM) } \\
\hline \multirow{2}{*}{ Total VFA } & All & 120.4 & 113.9 & & 3.51 & 0.088 & 0.389 & 0.679 & $<0.001$ & 0.205 & $<0.001$ & 0.007 & 0.439 \\
\hline & High & 123.0 & 113.4 & 122.7 & 6.47 & 0.313 & 0.846 & & $<0.001$ & 0.902 & 0.022 & 0.098 & 0.175 \\
\hline \multirow[t]{2}{*}{ Acetate (A) } & All & 71.4 & 70.3 & & 2.02 & 0.601 & 0.021 & 0.085 & $<0.001$ & 0.045 & 0.034 & 0.152 & 0.624 \\
\hline & High & 67.2 & 67.8 & 74.9 & 3.50 & 0.129 & 0.107 & & $<0.001$ & 0.801 & 0.236 & 0.474 & 0.215 \\
\hline \multirow{2}{*}{ Propionate (P) } & All & $30.2^{\mathrm{a}}$ & $22.3^{\mathrm{b}}$ & & 1.79 & $<0.001$ & $<0.001$ & 0.110 & $<0.001$ & 0.098 & $<0.001$ & $<0.001$ & 0.019 \\
\hline & High & 39.9 & 26.2 & 26.9 & 3.58 & 0.071 & 0.049 & & $<0.001$ & 0.606 & $<0.001$ & $<0.001$ & 0.197 \\
\hline \multirow[t]{2}{*}{$\mathrm{A}: \mathrm{P}$} & All & $2.74^{\mathrm{a}}$ & $3.39^{\mathrm{b}}$ & & 0.16 & 0.002 & $<0.001$ & 0.186 & $<0.001$ & 0.083 & $<0.001$ & 0.002 & 0.742 \\
\hline & High & 1.84 & 2.82 & 3.01 & 0.30 & 0.067 & 0.031 & & $<0.001$ & 0.438 & $<0.001$ & 0.063 & 0.038 \\
\hline \multirow[t]{2}{*}{ Butyrate (B) } & All & $13.5^{\mathrm{a}}$ & $16.2^{\mathrm{b}}$ & & 0.80 & 0.006 & $<0.001$ & 0.197 & $<0.001$ & 0.025 & $<0.001$ & 0.640 & 0.865 \\
\hline & High & 10.3 & 14.5 & 15.4 & 1.57 & 0.125 & 0.143 & & $<0.001$ & 0.855 & 0.025 & 0.836 & 0.619 \\
\hline \multirow{2}{*}{$(\mathrm{A}+\mathrm{B}) / \mathrm{P}$} & All & $3.28^{\mathrm{a}}$ & $4.17^{\mathrm{b}}$ & & 0.22 & 0.001 & $<0.001$ & 0.218 & $<0.001$ & 0.097 & $<0.001$ & $<0.001$ & 0.816 \\
\hline & High & 2.11 & 3.41 & 3.63 & 0.40 & 0.077 & 0.033 & & $<0.001$ & 0.467 & $<0.001$ & 0.053 & 0.126 \\
\hline \multirow[t]{2}{*}{ Valerate } & All & $2.29^{\mathrm{a}}$ & $1.77^{\mathrm{b}}$ & & 0.16 & 0.007 & $<0.001$ & 0.006 & $<0.001$ & 0.018 & $<0.001$ & $<0.001$ & $<0.001$ \\
\hline & High & 2.94 & 2.00 & 2.14 & 0.35 & 0.070 & 0.013 & & $<0.001$ & 0.067 & $<0.001$ & $<0.001$ & 0.001 \\
\hline \multirow[t]{2}{*}{ D-Lactate } & All & $0.06^{\mathrm{a}}$ & $0.44^{\mathrm{b}}$ & & 0.09 & 0.002 & 0.377 & 0.194 & $<0.001$ & 0.637 & $<0.001$ & 0.988 & 0.990 \\
\hline & High & $0.04^{\mathrm{a}}$ & $0.60^{\mathrm{b}}$ & $0.29^{\mathrm{a}}$ & 0.14 & $<0.001$ & 0.132 & & $<0.001$ & 0.657 & $<0.001$ & 0.406 & 0.948 \\
\hline \multirow{2}{*}{ Ammonia } & All & 7.07 & 8.02 & & 0.99 & 0.358 & 0.001 & 0.221 & $<0.001$ & 0.255 & $<0.001$ & $<0.001$ & 0.051 \\
\hline & High & $3.79^{\mathrm{a}}$ & $5.59^{\mathrm{a}}$ & $11.36^{\mathrm{b}}$ & 1.34 & 0.011 & 0.071 & & $<0.001$ & 0.566 & $<0.001$ & 0.099 & 0.104 \\
\hline \multirow[t]{2}{*}{$\mathrm{pH}$} & All & $6.07^{\mathrm{a}}$ & $6.25^{\mathrm{b}}$ & & 0.06 & 0.009 & 0.007 & 0.473 & $<0.001$ & 0.645 & $<0.001$ & $<0.001$ & 0.926 \\
\hline & High & 5.94 & 6.18 & 6.13 & 0.09 & 0.092 & 0.893 & & $<0.001$ & 0.935 & $<0.001$ & 0.108 & 0.840 \\
\hline
\end{tabular}

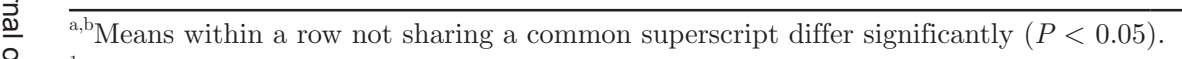

음 $\quad{ }^{1} \mathrm{All}=$ supplement feeding amounts $8,10,12,14$, and $16 \mathrm{~kg}$ of DM total supplement/cow per day; High = supplement feeding amounts 14 and $16 \mathrm{~kg}$ of DM total supplement/cow per day, to incorporate the effect of canola meal substitution.

${ }_{0}^{2} \mathrm{PMR}=$ partial mixed ration; PMR + canola $=\mathrm{PMR}+$ canola meal.

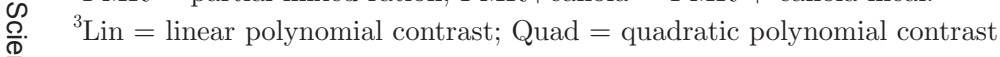


obtained using discriminant analysis of standardized variates of ruminal concentrations of the individual VFA: acetate, butyrate, propionate, valerate, isovalerate, isobutyrate, and caproate, and total lactate and concentrations of ruminal ammonia and ruminal $\mathrm{pH}$ defined according to the methods of Bramley et al. (2008). Acidosis eigenvalues were based on the statistical distance of each sample from the centroid for known cases of ruminal acidosis identified in the data set of Bramley et al. (2008). Eigenvalues that approached 1 are in the center of the acidosis category and those approaching 0 are not acidotic.

\section{RESULTS}

A linear decrease in milk fat percentage with increased supplement amount fed was a clinical sign consistent with ruminal acidosis; however, diarrhea and lameness were not observed in any of the cows during the experiment. Acidosis eigenvalues showed that control cows fed $16 \mathrm{~kg}$ of SDM had ruminal acidosis (Table 5; Figure 1). Milk data were not recorded for a control cow fed $12 \mathrm{~kg}$ of SDM during the measurement period, as she ceased production.

\section{DMI}

Total DMI was within $1 \mathrm{~kg}$ of DM of the target total DMI for the controls, but was up to $1.8 \mathrm{~kg}$ of DM higher than the target DMI in the PMR and PMR+canola cows (Table 1). Differences between target and actual DMI of total supplement did not exceed $1 \mathrm{~kg}$ of DM for the controls, regardless of supplement feeding amount. The DMI of total supplement for the PMR and PMR+canola cows exceeded the target intakes for all supplement feeding amounts by between 0.4 to 1.5 $\mathrm{kg}$ of DM/cow per day. Pasture DMI for the controls was higher for all supplement feeding amounts except the 12 and $16 \mathrm{~kg}$ of DM feeding groups compared with the target DMI and was similar to the target DMI for pasture in the PMR and PMR+canola cows. The DMI of crushed wheat was lower than the target DMI for all control cows, regardless of supplement feeding amount. The controls had from 0.3 to $0.8 \mathrm{~kg}$ of DM higher DMI of ryegrass silage than the target DMI (Table 1).

All Supplement Feeding Amounts. Pasture DMI was not influenced by feeding strategy; however, the total daily DMI and DMI of total supplement were higher in the PMR compared with control cows. Pasture DMI, total supplement DMI, and total daily DMI increased linearly with supplement feeding amount (Table 4).

High Supplement Feeding Amounts. Pasture DMI was higher in the control compared with PMR and PMR+canola cows, highest in the control cows fed
$14 \mathrm{~kg}$ of SDM, and lower in the cattle fed $16 \mathrm{~kg}$ of SDM. The DMI of total supplement was lower in the control compared with the PMR and PMR+canola cows and higher in cows fed 16 compared with $14 \mathrm{~kg}$ of SDM. Total daily DMI was lower in the control compared with the PMR cows and highest in the PMR+canola cows, and was higher in the cows fed 16 compared with $14 \mathrm{~kg}$ of SDM (Table 4).

\section{Milk Measures}

Greater variation in milk measures occurred in the fistulates compared with the herd (data not shown). The feeding strategy $\times$ supplement feeding amount interaction was not significant for any milk measures (Table 4).

All Supplement Feeding Amounts. Yields of fat tended to increase in the PMR cows compared with control cows, but feeding strategy had no other effects on milk measures. Yields of milk, ECM, and protein increased linearly with supplement feeding amount, and fat percentage decreased linearly with supplement feeding amount (Table 4).

High Supplement Feeding Amounts. Yield of ECM and protein were higher in the cows fed PMR+canola compared with the control and PMR cows. Fat yield was higher in the PMR cows than the control cows and was highest in the PMR + canola-fed cows. A similar trend was observed for fat percentage. Protein percentage was higher in the cows fed $16 \mathrm{com}-$ pared with $14 \mathrm{~kg}$ of SDM (Table 4).

\section{Ruminal Measures}

For all supplement feeding amounts and the high supplement feeding amounts, total and individual VFA and ammonia concentrations had a biphasic pattern over time, with peaks in concentrations occurring at times 3 and 6 . The opposite pattern was observed for ruminal $\mathrm{pH}$ over time. Concentrations of D-lactate were relatively stable over time except for an increase in concentration in the PMR and PMR+canola cows at time 5 (the first sampling time after the afternoon feed).

All Supplement Feeding Amounts. Acidosis eigenvalues were lower by $0.2 \pm 0.07$ units in the PMRfed cows compared with the controls, and had a linear and quadratic increase with supplement feeding amount (Table 5). Eigenvalues were higher in the controls from times 3 to 9 (Figure 1B) and were higher in the cattle fed $16 \mathrm{~kg}$ of SDM at times 2 to 10, and the cows fed $14 \mathrm{~kg}$ of SDM at times 3 and 4, compared with those fed 8 to $12 \mathrm{~kg}$ of SDM (Figure 1C). Peaks in acidosis eigenvalues occurred at times 4 and 7 (Figure 1B). 

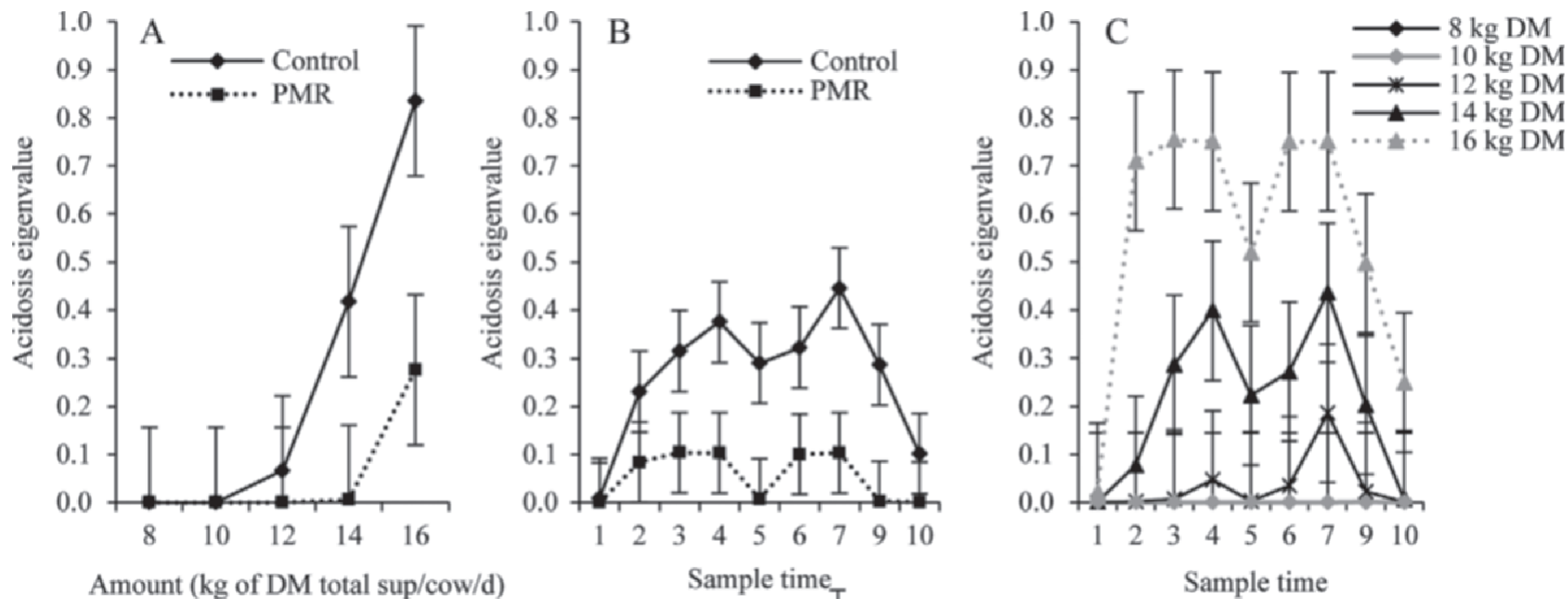

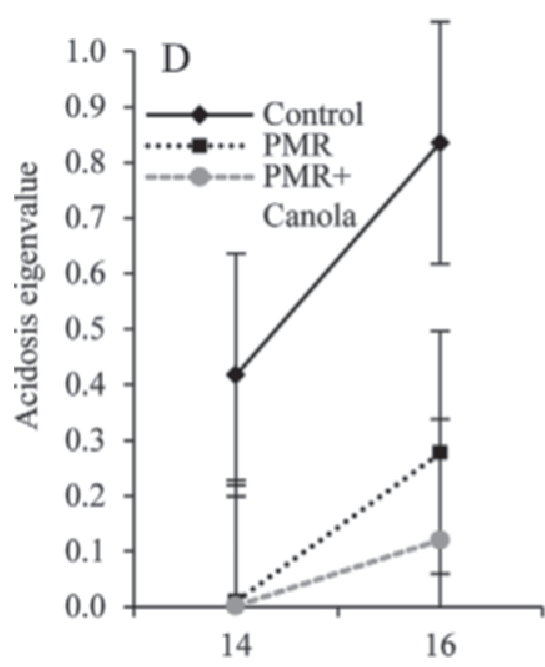

Amount ( $\mathrm{kg}$ of DM total sup/cow/d)

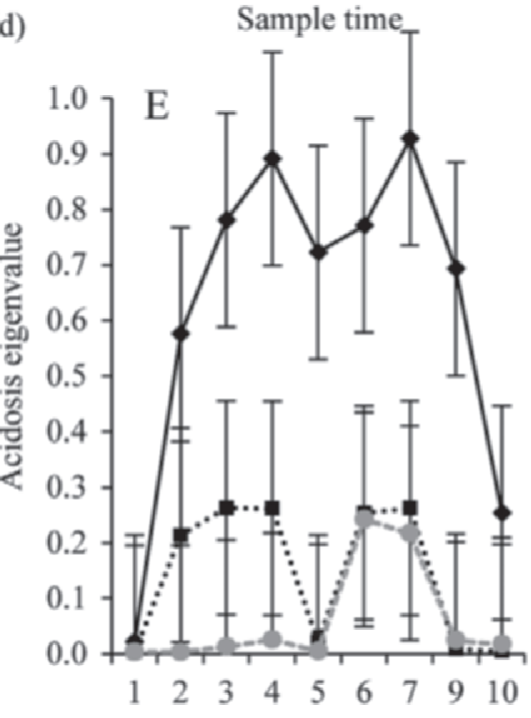

Sample time

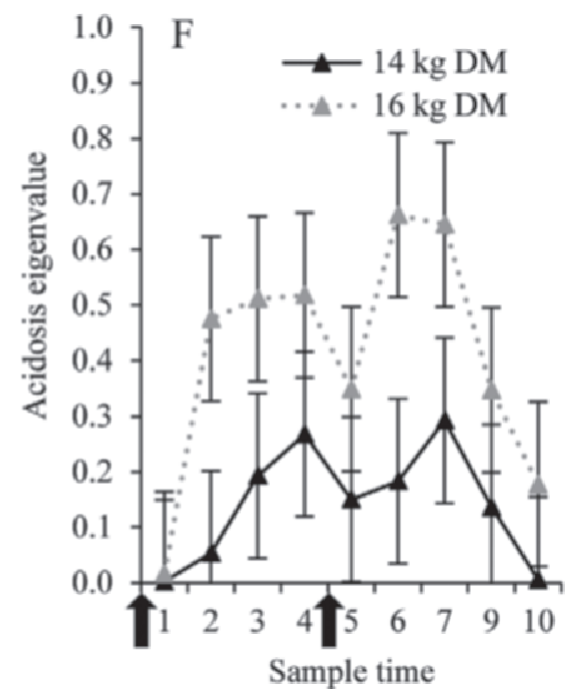

Figure 1. Mean $( \pm \mathrm{SEM})$ acidosis eigenvalues for dairy cows from all feeding groups showing interactions between (A) feeding strategy and supplement feeding amount, (B) feeding strategy and sample time, and (C) supplement feeding amount and sample time. Mean ( \pm SEM) acidosis eigenvectors for dairy cows from the high supplement feeding amount groups only (14 and $16 \mathrm{~kg}$ of DM of total supplement/cow per day) showing interactions between (D) feeding strategy and supplement feeding amount, (E) feeding strategy and sample time, and (F) supplement feeding amount and sample time. Sample times were approximately $2.4 \mathrm{~h}$ apart over a 24 -h period. Sample time 1 was approximately $0820 \mathrm{~h}$ and milking was at 0700 and $1500 \mathrm{~h}$ (black arrows). PMR $=$ partial mixed ration; PMR + canola $=\mathrm{PMR}+$ canola meal; amount $=\mathrm{kg}$ of $\mathrm{DM}$ of total supplement/cow per day.

Concentrations of D-lactate and butyrate, the acetate to propionate ratio, the lipogenic to gluconeogenic VFA ratio [(acetate + butyrate)/propionate], and $\mathrm{pH}$ were higher in the PMR cows compared with the controls, whereas propionate and valerate concentrations were lower in the PMR cows compared with control cows. Total VFA, acetate, and ammonia concentrations were not influenced by feeding strategy (Table 5).

The acetate to propionate ratio, the lipogenic to gluconeogenic VFA ratio, $\mathrm{pH}$, and acetate, butyrate, and ammonia concentrations linearly decreased with supplement feeding amount. Propionate concentration linearly increased with supplement feeding amount and valerate concentration linearly and quadratically increased with supplement feeding amount (Table 5).

Propionate and valerate concentrations were the only ruminal measures with a 3 -way interaction between feeding strategy, supplement feeding amount, and sample time. Acetate concentration was higher in the control cows fed 8 and $10 \mathrm{~kg}$ of SDM and lower in control cows fed $12 \mathrm{~kg}$ of SDM compared with the PMR cows. Butyrate concentrations were increased in the PMR cows fed 12 to $16 \mathrm{~kg}$ of SDM compared with the controls. Valerate concentration was higher in the 

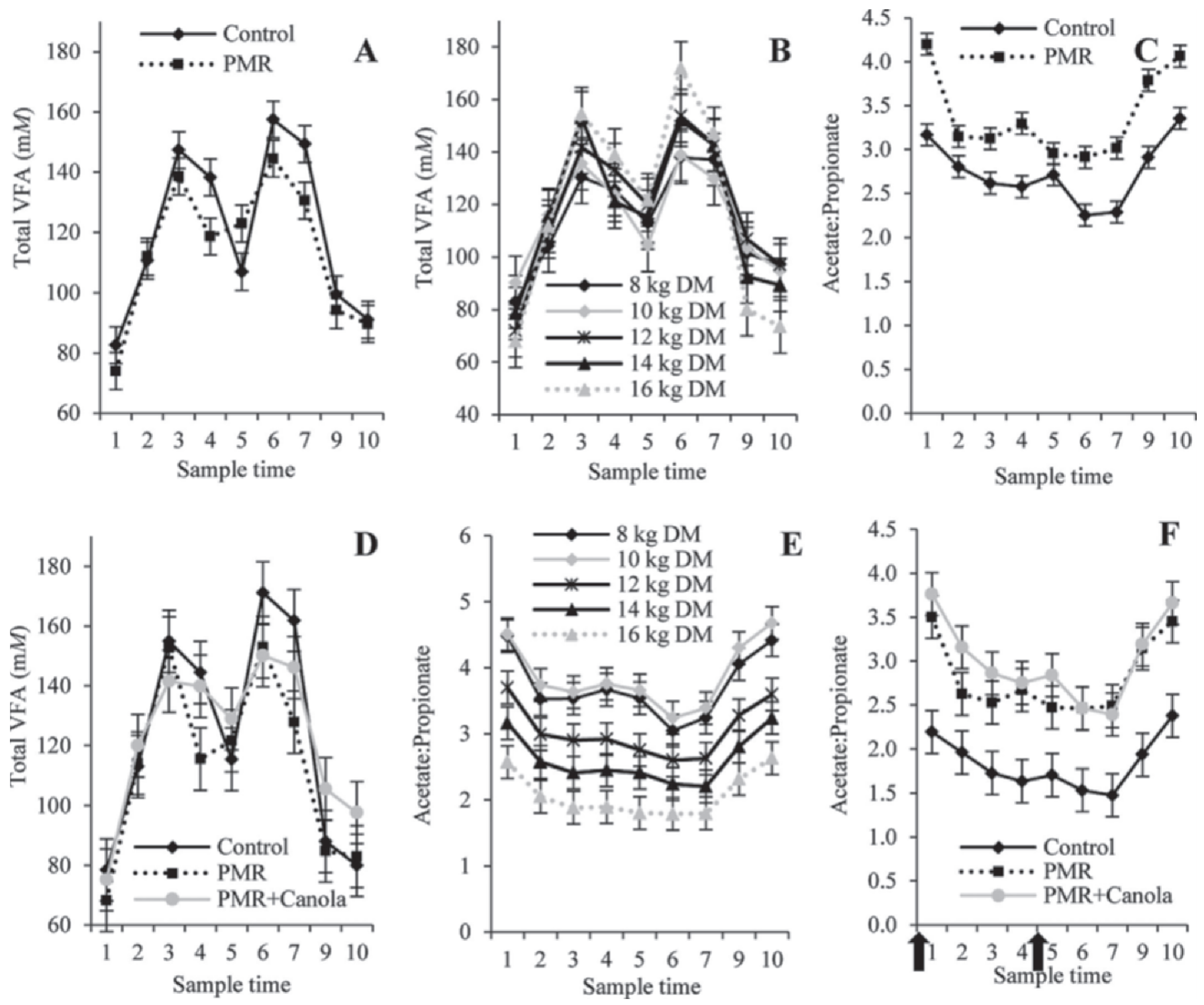

Figure 2. Mean interactions for (A) total VFA concentrations between feeding strategy and sample time from all feeding groups $(\mathrm{n}=24$ cows), (B) total VFA concentrations between supplement feeding amounts and sample time from all feeding groups ( $\mathrm{n}=24$ cows), (C) acetate to propionate ratio between feeding strategy and sample time from all feeding groups $(\mathrm{n}=24$ cows), (D) total VFA concentrations for between feeding strategy and sample time from cattle fed only 14 and $16 \mathrm{~kg}$ of total supplement/cow per day ( $\mathrm{n}=12$ cows), (E) acetate to propionate ratio between supplement feeding amount and sample time from all feeding groups $(\mathrm{n}=24$ cows $)$, and $(\mathrm{F})$ acetate to propionate ratio between feeding strategy and sample time from cattle fed only 14 and $16 \mathrm{~kg}$ of total supplement/cow per day ( $\mathrm{n}=12$ cows). Sample times were approximately $2.4 \mathrm{~h}$ apart over a 24-h period. Sample time 1 was approximately $0820 \mathrm{~h}$ and milking was at 0700 and $1500 \mathrm{~h}$ (black arrows). PMR = partial mixed ration; PMR + canola $=\mathrm{PMR}+$ canola meal; amount $=\mathrm{kg}$ of DM of total supplement/cow per day.

control cows fed $16 \mathrm{~kg}$ of SDM compared with others (Table 5).

Total VFA (Figure 2A), acetate, propionate, and valerate concentrations were higher in control cows at times 3 and 6 and lower at time 5 . The acetate to propionate ratio (Figure 2C), the lipogenic to gluconeogenic VFA ratio, $\mathrm{pH}$, and butyrate concentrations were greater over time in the PMR-fed cattle (Table 5).
Total VFA concentrations were lower in cows fed 16 $\mathrm{kg}$ of SDM at times 9 and 10 compared with cattle fed 8 and $12 \mathrm{~kg}$ of SDM, and were higher in cattle fed 16 compared with 8 and $10 \mathrm{~kg}$ of SDM at time 6 (Figure 2B). Propionate and valerate concentrations were higher for cows fed $16 \mathrm{~kg}$ of SDM than for all other supplement feeding amounts at times 3 to 6 . The acetate to propionate (Figure $2 \mathrm{E}$ ) and lipogenic to 
gluconeogenic VFA ratios decreased with supplement feeding amount across time, with the highest ratios at times 1 and 10. Ruminal $\mathrm{pH}$ decreased with supplement feeding amount and was lowest at times 3 and 6 . Ammonia concentration was greater in the PMR cows at times 2, 3, and 5, and lower at time 7 .

High Supplement Feeding Amounts. Acidosis eigenvalues were higher in the control compared with PMR and PMR+canola cows between times 3 and 9 (Figure 1E) and peaked at times 4 and 7. D-Lactate concentration was increased in PMR cows compared with control and PMR+canola cows, and ammonia concentration was increased in the PMR+canola cows. Propionate and valerate concentrations were increased in the cows fed 16 compared with $14 \mathrm{~kg}$ of SDM, and the acetate to propionate and lipogenic to gluconeogenic VFA ratios were decreased in the cows fed 16 $\mathrm{kg}$ of SDM compared with $14 \mathrm{~kg}$ of SDM. A 3-way interaction of feeding strategy $\times$ supplement feeding amount $\times$ time occurred for valerate concentration, but no 2-way interaction of feeding strategy $\times$ supplement feeding amount was significant for any ruminal measures (Table 5).

Total VFA (Figure 2D), propionate, and valerate concentrations, the acetate to propionate ratio (Figure $2 \mathrm{~F}$ ), the lipogenic to gluconeogenic VFA ratio, and $\mathrm{pH}$ had similar patterns across time for each feeding strategy when all supplement feeding amounts were analyzed. The PMR+canola cows produced similar results to the PMR cows over time for these measures, except for an increase in $\mathrm{pH}$ in $\mathrm{PMR}+$ canola cows compared with control and PMR cows at time 3. Ammonia concentrations were higher in the PMR + canola cows from times 1 to 7 compared with the control and PMR cows and peaked at times 3 and 6 . Propionate and valerate concentrations were higher in the cows fed $16 \mathrm{~kg}$ of SDM over time compared with those fed $14 \mathrm{~kg}$ of DM, similar to when all supplement feeding amounts were analyzed (Table 5).

\section{Bacterial Diversity Analysis}

Rarefaction analysis (Hughes et al., 2001), which is used to estimate the depth of coverage of diversity of ruminal bacteria within ruminal fluid samples (Kim et al., 2011), indicated that coverage of bacterial diversity appeared sufficient to evaluate BCC. Sampling saturation of OTU had not yet been met. The PMR cows fed $10 \mathrm{~kg}$ of SDM had the highest number of observed OTU $(722 \pm 50)$ and the control cows fed $16 \mathrm{~kg}$ of SDM had the lowest (254 \pm 29 ; Figure 3$)$.

The overall microbiomes of the cows were not distinctly different in their BCC, with only 6 and $4.5 \%$ of the variance being explained, which could not be attributed to any of the groupings (data not shown). However, distinct variation (Monte Carlo $P=0.001$ ) in the 16S rDNA-estimated BCC occurred among feeding strategies at the species level in a between-group constrained principal component analysis (PCoA) that captured $100 \%$ of the sample variation (Figure 4A). The first principal component (PC) of the betweengroup analysis accounted for $57.8 \%$ of the variation between feeding strategies, and the second PC accounted for $42.2 \%$ (Figure $4 \mathrm{~A}$ ). Bacterial community composition was the most distinct between the control and PMR+canola cows. Spatial heterogeneity among cows was relatively large and was greatest in the control-fed cows (Figure 4A).

The between-group constrained PCoA identified variation in $16 \mathrm{~S}$ rDNA-estimated $\mathrm{BCC}$ among groups from different feeding strategy and supplement feeding amount combinations (Monte Carlo $P=0.001$ ). This variation was not as distinct as that between feeding strategy groups alone, which accounted for $37.4 \%$ of the variation (Figure 4B). The first PC accounted for $22.4 \%$ of the variation between feeding strategies, and the second PC accounted for 15.0\% (Figure 4B). Bacterial community composition was not different among control cows fed 8 and 10, PMR cows fed 8, 10, 12, and 14, and PMR+canola cows fed $14 \mathrm{~kg}$ of SDM (Figure 4B); however, the BCC of these tightly clustered groups differed from that of the remaining groups. Bacterial community composition was similar between PMR cows fed $16 \mathrm{~kg}$ of SDM and PMR+canola cows fed $16 \mathrm{~kg}$ of SDM, and these 2 groups had the greatest spatial heterogeneity (Figure 4B). The control cows fed 12 and $14 \mathrm{~kg}$ of SDM also had a relatively large spatial heterogeneity and similarity in BCC. The control cows fed $16 \mathrm{~kg}$ of SDM had the most distinct BCC with, uniquely, no overlap of composition observed (Figure 4B).

Distinct BCC occurred among each of the 3 ruminal fluid sample times (Figure 4C; Monte Carlo $P=0.001$ ). A total of $100 \%$ of the variation was accounted for by the first 2 PC: PC1 accounted for $63.9 \%$ and PC2 accounted for $36.2 \%$ of the variation (Figure $4 \mathrm{C}$ ).

\section{Bacterial Prevalence}

A total of 12 phyla and 1 candidate phyla were identified within the ruminal bacterial population from $16 \mathrm{~S}$ rDNA gene pyrosequences. The majority of sequences were represented by the Firmicutes or Bacteroidetes phyla, accounting for a combined total of $84.2 \%$ of sequences; 49.9 and $34.3 \%$ of total sequences on average, respectively. The candidate phyla TM7 represented $6.3 \%$ and the phylum Tenericutes represented $5.4 \%$ of the total sequences on average. The remaining microbiota 


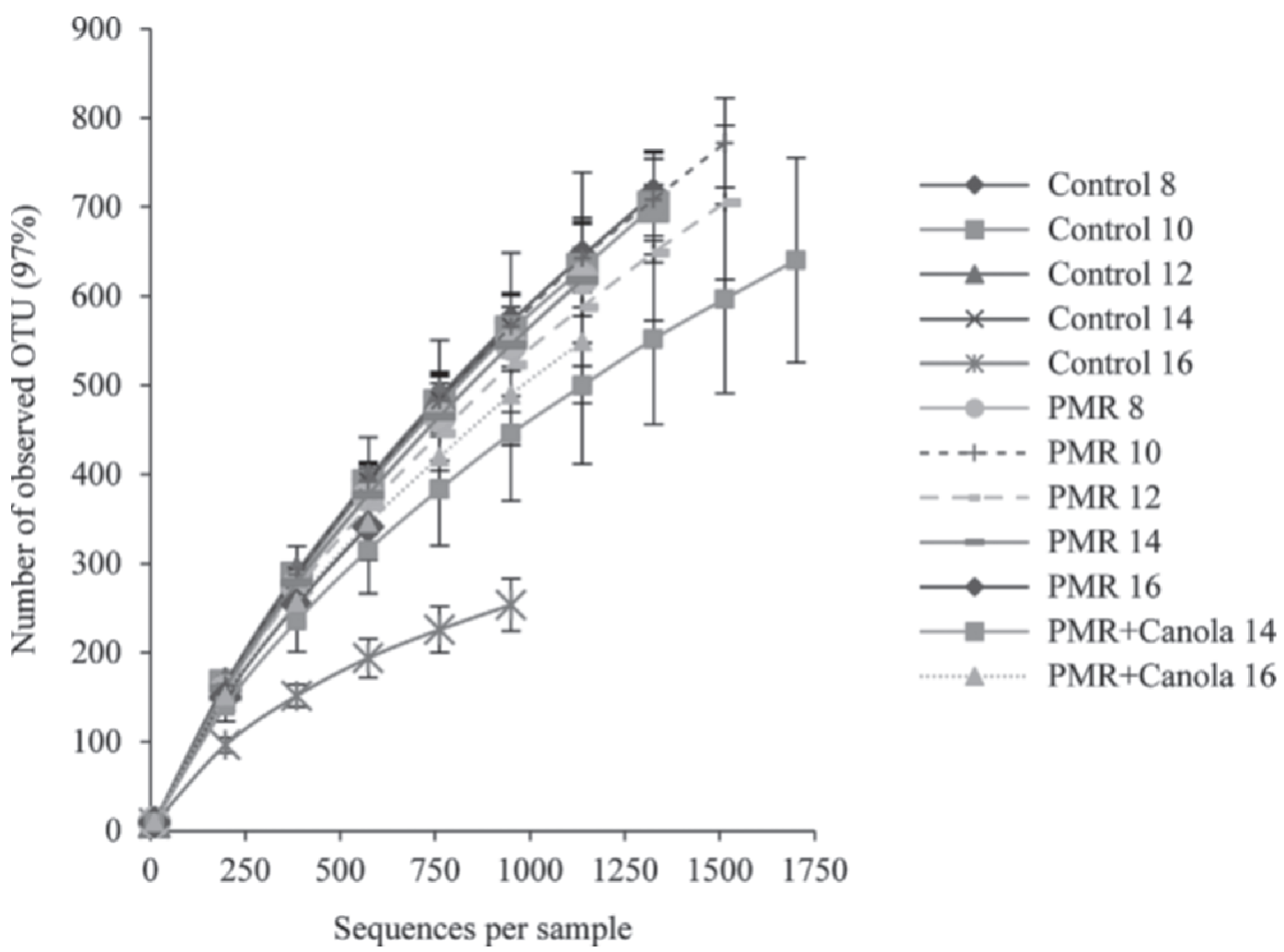

Figure 3. Rarefaction curves for each feeding group consisting of the mean number of observed operational taxonomic units (OTU) \pm SEM. The OTU were calculated with a $3 \%$ disparity. Numbers $8,10,12,14$, and 16 denote the amount $(\mathrm{kg})$ of DM of total supplement fed/cow per day. $\mathrm{PMR}=$ partial mixed ration; PMR + canola $=\mathrm{PMR}+$ canola meal.

was composed of phyla with low relative abundances. A total of 44 bacterial families were identified, and the Prevotellaceae, Ruminococcaceae, and Lachnospiraceae families and the unclassified Clostridiales had the largest relative abundances, at $30.9,21.3,11.3$, and $11.7 \%$, respectively. In total, 64 genera were identified, with Prevotella being the predominant genus. These represented approximately $30.1 \%$ of the relative abundance of bacterial sequences, ranging from an average of 13.0 to $50.7 \%$ among groups.

When all supplement feeding groups were analyzed, members of the Prevotella genus were lower in relative abundance in the PMR compared with control cows (mean \pm SED of relative abundance $=30.0$ and $38.6 \%$ $\pm 4.77 ; P=0.03)$. Relative abundance of members of the Lactobacillus, Streptococcus, and Butyrivibrio genera were higher in the PMR $(0.12 \% \pm 0.03,0.05 \% \pm$ 0.01 , and $3.42 \% \pm 0.57$; respectively), compared with control cows $(0.00 \% \pm 0.03,0.01 \% \pm 0.01$, and $1.52 \%$ $\pm 0.57 ; P=0.001,0.001$, and 0.006 , respectively). The relative abundance of the Megasphaera, Selenomonas, and Veillonella genera were not influenced by feeding strategy. The Butyrivibrio linearly increased in relative abundance with supplement feeding amount $(P=0.05)$; however, feeding amount had no effect on the relative abundance of the Prevotella, Lactobacillus, Streptococcus, Megasphaera, Selenomonas, and Veillonella genera. When only the high supplement feeding amount groups were analyzed, feeding strategy and supplement feeding amount did not affect the Prevotella, Lactobacillus, Butyrivibrio, Megasphaera, Selenomonas, or Veillonella genera, but Streptococcus was lower in control cows compared with PMR- and PMR+canola-fed cows (0.06, 0.05 , and $0.00 \% \pm 0.02$, respectively; $P=0.039$ ).

The main effects and the interactions of feeding strategy, supplement feeding amount, and sample time for bacterial families with a mean relative abundance of $>0.2 \%$ in at least one feeding strategy for all cows are displayed in Table 6 . These main effects and interactions are also displayed for cows fed 14 and $16 \mathrm{~kg}$ of SDM, incorporating the effect of canola substitution (Table 6). The Streptococcaceae and Lactobacillaceae were among the bacterial families that had a mean relative abundance of $>0.2 \%$ in at least one feeding strategy.

All Supplement Feeding Amounts. Relative abundances of the following bacterial families were increased in the control compared with PMR cows: 

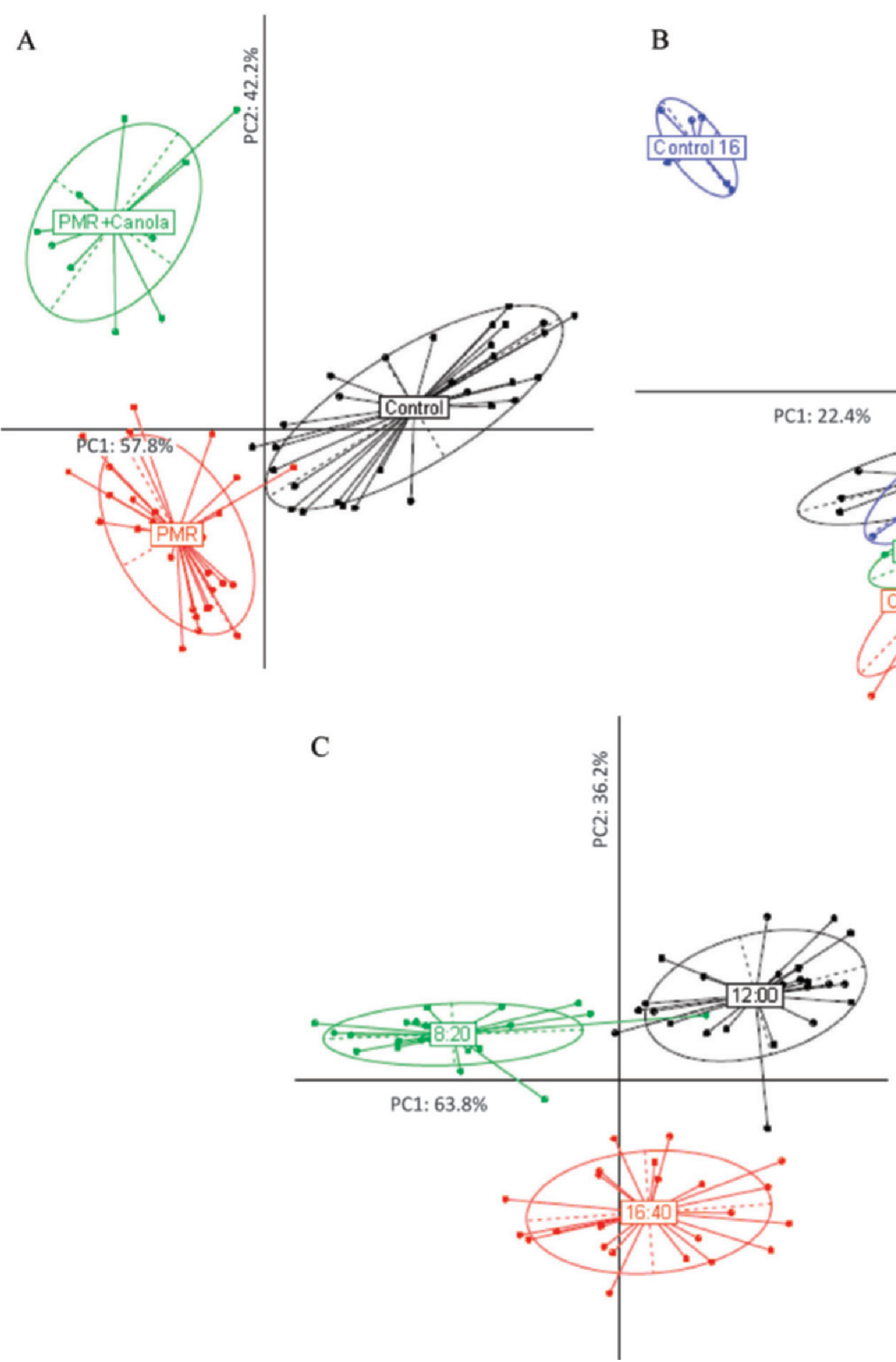

Figure 4. Constrained between-group principal coordinates (PC) analysis of bacterial 16S rDNA gene sequences at the species level from ruminal fluid samples from dairy cattle (A) fed 1 of 3 feeding strategies: control ( $\mathrm{n}=10$ cows; $\mathrm{n}=30$ samples), partial mixed ration (PMR; $\mathrm{n}$ $=10$ cows; $\mathrm{n}=30$ samples), or PMR +canola (PMR + canola meal; $\mathrm{n}=4$ cows; $\mathrm{n}=12$ samples), (B) fed 1 of 3 feeding strategies: control ( $\mathrm{n}$ $=10$ cows $), \operatorname{PMR}(\mathrm{n}=10$ cows $)$, or PMR + canola $(\mathrm{n}=4 \mathrm{cows})$ at one of the following supplement feeding amounts $8,10,12,14$, or $16 \mathrm{~kg}$ of DM of total supplement/cow per day (2 cows per amount from each feeding strategy; $\mathrm{n}=6$ samples per amount from each feeding strategy), and (C) collected at 1 of 3 sample times: 0820, 1200, and $1640 \mathrm{~h}$. All ruminal fluid samples were collected on d 19 of diet supplementation. Each point on the plot represents the bacterial community composition of a single sample (cow by feeding strategy by supplement feeding amount by sample time combination) with a greater distance between points indicating a greater difference in bacterial community composition. Color version available in the online PDF. 
Prevotellaceae, Erysipelotrichaceae, Veillonellaceae, and Fibrobacteraceae. Relative abundances of the following bacterial families decreased in the control compared with the PMR cows: Ruminococcaceae, unclassified Clostridiales, Anaerolinaceae, Clostridiales Family XIII incertae sedis, Bacillaceae, and Acetobacteraceae. Relative abundances of Lachnospiraceae, unclassified Bacteroidales, F16, Coriobacteriaceae, unclassified RF39, and Catabacteriaceae were not influenced by feeding strategy.

The relative abundance of Ruminococcaceae and unclassified Clostridiales linearly and quadratically decreased with supplement feeding amount. The relative abundance of Lachnospiraceae, unclassified Bacteroidales, Fibrobacteraceae, and Acetobacteraceae linearly increased with supplement feeding amount, whereas that of Erysipelotrichaceae was both linearly and quadratically increased. Anaerolinaceae and Catabacteriaceae linearly decreased in relative abundance with supplement feeding amount.

The relative abundances of F16, Coriobacteriaceae, Anaerolinaeceae, Clostridiales Family XIII incertae sedis, Bacillaceae, and Acetobacteraceae increased, whereas Veillonellaceae and Fibrobacteraceae decreased over the sample times. The relative abundance of Ruminococcaceae, unclassified Clostridiales, Lachnospiraceae, and Catabacteriaceae increased in samples collected at $1200 \mathrm{~h}$ compared with those collected at 0820 and $1640 \mathrm{~h}$, and the inverse occurred for Prevotellaceae and unclassified Bacteroidales.

The Ruminococcaceae linearly and quadratically decreased in relative abundance with supplement feeding amount in the control and PMR cows, respectively. The relative abundance of the unclassified Clostridiales and Veillonellaceae linearly and quadratically decreased in the controls with supplement feeding amount, respectively. The Erysipelotrichaceae increased linearly and quadratically in relative abundance in the controls with supplement feeding amount. The relative abundance of the unclassified Bacteroidales linearly and quadratically increased in the PMR cows and quadratically decreased in the controls with supplement feeding amount. The Anaerolineaceae linearly and quadratically decreased in relative abundance with supplement feeding amount in the control and PMR cows, respectively. The Acetobacteraceae linearly and quadratically increased in the PMR cows with supplement feeding amount (Table 6).

High Supplement Feeding Amounts. The relative abundance of F16 was higher in the PMR and PMR+canola cows and similar between the control and PMR cows. Veillonellaceae and Acetobacteraceae increased and decreased in relative abundance in the control compared with PMR and PMR+canola cows, respectively. The relative abundance of the unclassified
Bacteroidales was higher in the PMR compared with control and PMR+canola cows. Relative abundances of Ruminococcaceae, unclassified Clostridiales, and $A n$ aerolinaceae decreased in cows fed $16 \mathrm{~kg}$ of SDM, and increases in Erysipelotrichaceae and Acetobacteraceae occurred for these cows.

Prevotellaceae, Ruminococcaceae, Lachnospiraceae, unclassified Clostridiales, Anaerolinaceae, Bacillaceae, and Acetobacteraceae had a consistent pattern of relative abundance over time compared with when all supplement feeding amounts were analyzed. The relative abundance of Veillonellaceae was decreased at $1200 \mathrm{~h}$, compared with at 0820 and $1640 \mathrm{~h}$, and the Catabacteriaceae were decreased in relative abundance at $1640 \mathrm{~h}$.

The Erysipelotrichaceae increased in relative abundance in the controls fed $16 \mathrm{~kg}$ of SDM compared with the PMR and PMR+canola cows fed 14 or $16 \mathrm{~kg}$ of SDM, and relative abundance of this bacterial family decreased in the PMR cows fed $16 \mathrm{~kg}$ of SDM compared with control and PMR+canola cows fed $16 \mathrm{~kg}$ of SDM. The unclassified Bacteroidales were increased in relative abundance in the controls fed $14 \mathrm{~kg}$ of SDM compared with the other feeding strategies fed at this amount and the control and PMR+canola cows fed $16 \mathrm{~kg}$ of SDM. The relative abundance of unclassified Bacteroidales was lower in the control cows fed $16 \mathrm{~kg}$ of SDM compared with cows fed by all feeding strategies at 14 and $16 \mathrm{~kg}$ of SDM except the PMR+canola cows fed $14 \mathrm{~kg}$ of SDM (Table 6).

\section{Co-Inertia Analysis}

Co-inertia analysis showed that supplement feeding amount had the largest association with BCC. Bacterial community composition had the largest association with concentrations of the fermentation products ammonia, butyrate, valerate, and propionate, whereas time, $\mathrm{pH}$, and total VFA concentration were less associated (Figure 5). Bacterial community composition in PMR+canola cows fed $14 \mathrm{~kg}$ of SDM and PMR cows fed $12 \mathrm{~kg}$ of SDM was associated with concentrations of ruminal ammonia, butyrate, lactate, acetate, and $\mathrm{pH}$. An association was also observed between BCC of the controls fed 14 or $16 \mathrm{~kg}$ of SDM and ruminal propionate concentration. Valerate concentration was associated with BCC of controls fed $16 \mathrm{~kg}$ of SDM (Figure 5).

\section{DISCUSSION}

This experiment examined the effects of PMR and linearly increasing supplement feeding amounts on milk production, milk composition, and ruminal fermentation, ruminal acidosis, and ruminal BCC and their associations in late-lactation cows. Many of the feeding 
Table 6. Main effects and their interactions of feeding strategy (S), supplement feeding amount (A), and sample time (T), and their interactions, and means \pm SE of the difference (SED) for feeding strategy for bacterial families identified from 16S rDNA sequences with mean relative abundances of $>0.2 \%$ in at least one feeding strategy

\begin{tabular}{|c|c|c|c|c|c|c|c|c|c|c|c|c|c|}
\hline \multirow[b]{3}{*}{ Family } & \multirow[b]{3}{*}{ Amount $^{1}$} & \multicolumn{3}{|c|}{$\begin{array}{l}\text { Feeding strategy means }{ }^{2} \\
\text { (relative abundance, \%) }\end{array}$} & \multirow[b]{3}{*}{ SED } & \multicolumn{8}{|c|}{$P$-value } \\
\hline & & \multirow[b]{2}{*}{ Control } & \multirow[b]{2}{*}{ PMR } & \multirow[b]{2}{*}{ PMR+canola } & & \multirow[b]{2}{*}{$\mathrm{S}$} & \multicolumn{2}{|c|}{$\mathrm{A}^{3}$} & \multirow[b]{2}{*}{$\mathrm{T}$} & \multirow[b]{2}{*}{$\mathrm{S} \times \mathrm{A}$} & \multirow[b]{2}{*}{$\mathrm{S} \times \mathrm{T}$} & \multirow[b]{2}{*}{$\mathrm{A} \times \mathrm{T}$} & \multirow[b]{2}{*}{$\mathrm{S} \times \mathrm{A} \times \mathrm{T}$} \\
\hline & & & & & & & Lin & Quad & & & & & \\
\hline Prevotellaceae & All & $38.9^{\mathrm{a}}$ & $27.2^{\mathrm{b}}$ & \multirow{2}{*}{22.6} & 4.81 & 0.032 & 0.178 & \multirow[t]{2}{*}{0.361} & $<0.001$ & 0.123 & 0.018 & 0.063 & 0.324 \\
\hline \multirow{3}{*}{ Ruminococcaceae } & High & 46.8 & 29.6 & & 8.28 & 0.122 & 0.061 & & $<0.001$ & 0.811 & 0.764 & 0.648 & 0.108 \\
\hline & All & $18.0^{\mathrm{a}}$ & $24.5^{\mathrm{b}}$ & \multirow{2}{*}{20.1} & 2.58 & 0.026 & 0.001 & \multirow[t]{2}{*}{0.010} & $<0.001$ & 0.027 & 0.682 & 0.017 & 0.211 \\
\hline & High & 8.73 & 18.8 & & 4.43 & 0.264 & 0.014 & & 0.002 & 0.943 & 0.223 & 0.030 & 0.059 \\
\hline \multirow[t]{2}{*}{ Unclassified Clostridiales } & All & $10.35^{\mathrm{a}}$ & $13.20^{\mathrm{b}}$ & & 1.13 & 0.026 & $<0.001$ & \multirow[t]{2}{*}{0.038} & $<0.001$ & 0.009 & 0.251 & 0.148 & 0.440 \\
\hline & High & 4.66 & 12.77 & 10.86 & 2.11 & 0.114 & 0.044 & & $<0.001$ & 0.077 & 0.124 & 0.059 & 0.014 \\
\hline \multirow[t]{2}{*}{ Lachnospiraceae } & All & 12.9 & 10.6 & & 2.13 & 0.296 & 0.001 & \multirow[t]{2}{*}{0.074} & 0.001 & 0.877 & 0.002 & 0.018 & 0.009 \\
\hline & High & 17.8 & 14.9 & 9.24 & 4.69 & 0.369 & 0.082 & & 0.001 & 0.671 & 0.004 & 0.078 & 0.019 \\
\hline \multirow[t]{2}{*}{ F16 } & All & 2.30 & 6.89 & & 2.52 & 0.094 & 0.265 & 0.882 & 0.041 & 0.876 & 0.222 & 0.410 & 0.727 \\
\hline & High & $3.27^{\mathrm{a}}$ & $5.85^{\mathrm{ab}}$ & $12.4^{\mathrm{b}}$ & 3.88 & 0.009 & 0.074 & & 0.077 & 0.357 & 0.173 & 0.222 & 0.357 \\
\hline Erysipelotrichaceae & All & $5.16^{\mathrm{a}}$ & $3.06^{\mathrm{b}}$ & & 0.73 & 0.019 & $<0.001$ & 0.003 & 0.061 & $<0.001$ & $<0.001$ & 0.385 & 0.813 \\
\hline & High & 8.86 & 3.53 & 6.68 & 2.02 & 0.051 & 0.003 & & 0.143 & 0.009 & 0.499 & 0.119 & 0.709 \\
\hline Veillonellaceae & All & $4.63^{\mathrm{a}}$ & $2.60^{\mathrm{b}}$ & & 0.61 & 0.006 & 0.771 & 0.253 & $<0.001$ & 0.043 & 0.007 & 0.118 & 0.220 \\
\hline & High & $4.98^{\mathrm{a}}$ & $2.25^{\mathrm{b}}$ & $1.58^{\mathrm{b}}$ & 1.07 & 0.042 & 0.424 & & $<0.001$ & 0.061 & $<0.001$ & 0.150 & 0.458 \\
\hline Unclassified Bacteroidales & All & 3.27 & 3.52 & & 0.47 & 0.603 & 0.029 & 0.430 & 0.002 & $<0.001$ & 0.002 & 0.113 & 0.193 \\
\hline & High & $3.89^{\mathrm{a}}$ & $4.85^{\mathrm{b}}$ & $2.91^{\mathrm{a}}$ & 0.86 & 0.044 & 0.701 & & 0.598 & $<0.001$ & 0.030 & 0.669 & 0.156 \\
\hline Coriobacteriaceae & All & 0.97 & 2.28 & & 0.48 & 0.272 & 0.614 & 0.300 & $<0.001$ & 0.082 & 0.001 & 0.574 & 0.178 \\
\hline & High & 0.32 & 1.96 & 4.15 & 2.63 & 0.438 & 0.244 & & 0.062 & 0.328 & 0.229 & 0.395 & 0.492 \\
\hline Anaerolinaceae & All & $0.87^{\mathrm{a}}$ & $1.39^{\mathrm{b}}$ & & 0.23 & 0.044 & $<0.001$ & 0.509 & 0.002 & 0.035 & 0.116 & 0.911 & 0.581 \\
\hline & High & 0.09 & 0.82 & 1.25 & 0.45 & 0.164 & 0.005 & & 0.028 & 0.209 & 0.229 & 0.783 & 0.835 \\
\hline Clostridiales Family XIII & All & $0.82^{\mathrm{a}}$ & $1.34^{\mathrm{b}}$ & & 0.22 & 0.035 & 0.262 & 0.615 & $<0.001$ & 0.218 & 0.032 & 0.876 & 0.606 \\
\hline & High & 0.45 & 1.28 & 1.59 & 0.44 & 0.253 & 0.581 & & 0.083 & 0.691 & 0.579 & 0.731 & 0.746 \\
\hline Unclassified RF39 & All & 0.39 & 0.64 & & 0.16 & 0.155 & 0.709 & 0.578 & 0.583 & 0.775 & 0.373 & 0.881 & 0.885 \\
\hline & High & $0.31^{\mathrm{a}}$ & $0.65^{\mathrm{a}}$ & $1.38^{\mathrm{b}}$ & 0.38 & 0.031 & 0.409 & & 0.632 & 0.179 & 0.840 & 0.770 & 0.669 \\
\hline Catabacteriaceae & All & 0.49 & 0.48 & & 0.14 & 0.945 & 0.030 & 0.924 & 0.047 & 0.228 & 0.020 & 0.033 & 0.452 \\
\hline & High & 0.33 & 0.36 & 0.42 & 0.20 & 0.904 & 0.051 & & 0.022 & 0.184 & 0.010 & 0.021 & 0.009 \\
\hline Bacillaceae & All & $0.05^{\mathrm{a}}$ & $0.46^{\mathrm{b}}$ & & 0.15 & 0.018 & 0.381 & 0.816 & 0.001 & 0.688 & 0.014 & 0.576 & 0.771 \\
\hline & High & 0.02 & 0.52 & 0.44 & 0.35 & 0.504 & 0.503 & & 0.016 & 0.792 & 0.240 & 0.291 & 0.864 \\
\hline Fibrobacteraceae & All & $0.27^{\mathrm{a}}$ & $0.08^{\mathrm{b}}$ & & 0.08 & 0.039 & 0.008 & 0.275 & 0.037 & 0.275 & 0.116 & 0.270 & 0.070 \\
\hline & High & 0.56 & 0.13 & 0.10 & 0.18 & 0.084 & 0.600 & & 0.074 & 0.843 & 0.122 & 0.774 & 0.267 \\
\hline Acetobacteraceae & All & $0.00^{\mathrm{a}}$ & $0.28^{\mathrm{b}}$ & & 0.05 & $<0.001$ & $<0.001$ & 0.043 & $<0.001$ & 0.005 & $<0.001$ & $<0.001$ & 0.002 \\
\hline & High & $0.00^{\mathrm{a}}$ & $0.55^{\mathrm{b}}$ & $0.32^{\mathrm{b}}$ & 0.12 & 0.019 & 0.006 & & $<0.001$ & 0.094 & $<0.001$ & 0.004 & 0.101 \\
\hline
\end{tabular}

${ }^{\mathrm{a}, \mathrm{b}}$ Means within a row not sharing a common superscript differ significantly $(P<0.05)$.

${ }_{\varnothing}^{1}$ All = supplement feeding amounts $8,10,12,14$, and $16 \mathrm{~kg}$ of DM total supplement/cow per day; High = supplement feeding amounts 14 and $16 \mathrm{~kg}$ of DM total supplement/cow $\lesssim$ per day, to incorporate the effect of canola meal substitution.

$\stackrel{2}{2} \mathrm{PMR}=$ partial mixed ration; $\mathrm{PMR}+$ canola $=\mathrm{PMR}+$ canola meal

z $\quad{ }^{3} \operatorname{Lin}=$ linear polynomial contrast; Quad $=$ quadratic polynomial contrast. 


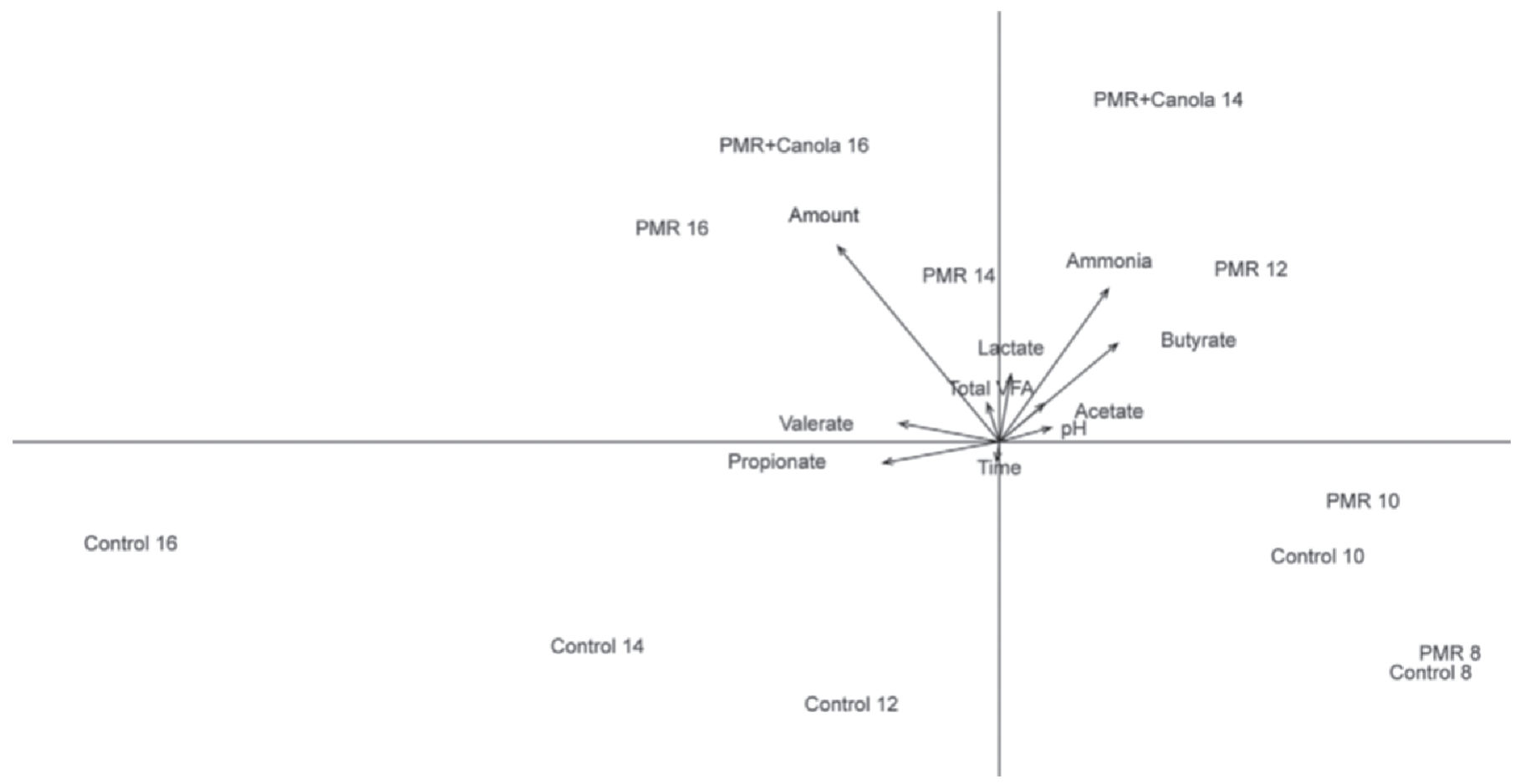

Figure 5. Duality diagram of co-inertia analysis of ruminal bacterial communities from $16 \mathrm{~S}$ rDNA 454 pyrosequences, measures of ruminal fermentation, sample time, and amount of total supplements fed in dairy cows fed 1 of 3 feeding strategies: control ( $\mathrm{n}=10 \mathrm{cows})$, partial mixed ration (PMR; $\mathrm{n}=10 \mathrm{cows})$, or PMR + canola (PMR + canola meal; $\mathrm{n}=4$ cows) at amounts $8,10,12,14$, or $16 \mathrm{~kg}$ of DM of total supplement/ cow per day (2 cows per amount at 3 times from each feeding strategy). On the bi-plot, the ruminal fermentation measures are represented as arrows. The direction of the arrow of each ruminal fermentation measure indicates an increasing magnitude of that measure. The angle between the arrows indicates their degree of correlation. The magnitude of the arrows indicates the importance of a measure on bacterial community composition. Measures with long arrows are more strongly correlated with the ordination axes than short arrows and have a greater influence on the pattern of variation (Carberry et al., 2012).

strategies and feeding amount combinations evaluated in this study are consistent with those fed on commercial farms (Bramley et al., 2012). The control feeding strategy mimics traditional twice-daily feeding of concentrates in the milking parlor, which is the dominant supplement feeding system on dairy farms in southeastern Australia (Bramley et al., 2012) and many other countries. Feeding supplements as a PMR is the second most dominant feeding system for dairy farming in this region (Bramley et al., 2012) and is designed to provide energy over a longer period compared with feeding an isoenergetic component-fed control diet (Bargo et al., 2003; Auldist et al., 2013).

It should be noted that although the control and PMR feeding strategies evaluated in this experiment were isoenergetic, they contained different feed components. The substitution of some wheat for canola meal in the PMR was designed to increase MP supply above NRC (2001) requirements. The removal of starch and the addition of protein, some of which provides ammonia and peptides, may result in better ruminal conditions and increased milk production. Although cows in the current study consumed a similar total DMI to target intakes, the control cows consumed less wheat and more ryegrass silage than targeted and were at a lower risk of ruminal acidosis than anticipated. These interventions were initiated in very late lactation, and milk production levels were consequently low.

The effects of feeding groups on the incidence of ruminal acidosis was assessed by the generation of acidosis eigenvalues using the model described by Bramley et al. (2008), which has been used to assess other data sets (O'Grady et al., 2008; Golder et al., 2012, 2014a). The eigenvalues are based on ruminal fermentation measures associated with health and production measures from 800 cows from 100 dairies that included pasture only, pasture and concentrate, PMR, and TMR feeding systems (Bramley et al., 2008, 2012). Thus, acidosis eigenvalues are a more comprehensive measure to diagnose ruminal acidosis compared with single measures such as ruminal $\mathrm{pH}$. The acidosis eigenvalues indicate that ruminal acidosis or rumen perturbation was present at different severities in the feeding groups. The acidosis eigenvalues in this study are consistent with expected physiological outcomes for the feeding groups and are consistent with the milk measures. The co- 
inertia analysis also supports the Bramley et al. (2008) model, with the strength and direction of relationships between feeding groups, ruminal fermentation, and ruminal BCC data coinciding with eigenvalues for feeding groups.

The acidosis eigenvalues of the control cows fed 14 or $16 \mathrm{~kg}$ of SDM indicate that these cows had the greatest incidence of ruminal acidosis. The control cows fed $16 \mathrm{~kg}$ of SDM also had the most distinct BCC in the constrained $\mathrm{PCoA}$ and co-inertia analysis and the lowest number of observed OTU in the rarefaction analysis. The linear and quadratic increase in acidosis eigenvalues with feeding amount is not surprising, as increasing the feeding amount provided an increase in dietary starch content. The quadratic decrease in yield of milk fat with feeding amount provides further support for this. Supplement feeding amount also had the largest influence on $\mathrm{BCC}$ of the measures tested in the co-inertia analysis, supporting these findings.

The PMR+canola cows had very low eigenvalues in cows fed both 14 and $16 \mathrm{~kg}$ of SDM, suggesting that these cows had the most favorable ruminal conditions of all feeding groups at higher feeding amounts. This favorable environment coincided with increased yields of ECM and milk fat in these groups of cows. Increased formation of MP may have contributed to the increase in yield of milk fat and ECM in the PMR+canola cows; however, in contrast, yields of milk and milk fat were not influenced by RUP content in the majority of studies quantitatively reviewed (Bargo et al., 2003). The involvement of dietary protein in ruminal acidosis and protein and carbohydrate synchrony requires further investigation.

The lower eigenvalues in cows fed the PMR compared with the controls indicate more favorable ruminal conditions and a lower incidence of ruminal acidosis in the PMR-fed cows. This finding may in part reflect the slower rate of fermentation of maize starch fed in the PMR compared with the rapid rate of fermentation of wheat starch, which predisposes cows to digestive disorders (Sutton, 1984; Khorasani et al., 2001). The more stable fermentation pattern that occurred in the PMR cows across the day, which may be more favorable, may also be partly because the maize grain and maize silage included in the PMR were consumed over a longer period than the wheat consumed by the control cows. Partial mixed ration feeding also allows simultaneous delivery of fermentable carbohydrates and physically effective fiber and better synchronization of starch and protein fermentation compared with feeding concentrates in the milking parlor followed by silage access on the pasture.

The effects of feeding strategy (Bargo et al., 2002b; Auldist et al., 2013, 2014) and increasing supplemen- tary feeding amount (Stockdale et al., 1987; Leddin et al., 2010; Auldist et al., 2013) on ruminal pH, total and individual VFA measures, and ammonia concentrations were generally consistent with similar studies. However, in contrast, propionate and valerate concentrations decreased and acetate to propionate ratio and butyrate concentrations increased in the PMR cows compared with control cows in our study. Ruminal $\mathrm{pH}$ was decreased with increased supplement feeding amount in the current study, but was not influenced in other studies (Stockdale et al., 1987; Leddin et al., 2010); however, those authors fed supplements only up to $10 \mathrm{~kg}$ of DM. Supplementation of the ionophore monensin and the antibiotic tylosin in the current study to all cows may also have reduced the generation of lactic acid (Dennis et al., 1981; Weimer et al., 2008) and influenced BCC. The spike in D-lactate concentration at sample time 5 in the PMR cows likely corresponded to the feeding of maize silage containing preformed lactic acid.

Concentrations of ammonia, butyrate, valerate, and propionate had a large influence on ruminal BCC, after feeding amount, supporting Bramley et al. (2008), who found that these are good predictors of ruminal acidosis. Ruminal $\mathrm{pH}$ had little influence on $\mathrm{BCC}$ in the co-inertia analysis (Figure 5), consistent with findings that cows with different $\mathrm{pH}$ profiles had similar BCC (Palmonari et al., 2010). In contrast, ruminal pH was a large vector in the study by Carberry et al. (2012), which examined associations between bacterial community diversity patterns and ruminal fermentation measures.

Protein supplementation did not influence total VFA concentration and molar proportions of acetate, propionate, and butyrate in the majority of studies in a quantitative review (Bargo et al., 2003), a finding consistent with this study. A higher ammonia concentration was associated with $\mathrm{BCC}$ in the $\mathrm{PMR}+$ canola cows fed $14 \mathrm{~kg}$ of SDM in the co-inertia analysis (Figure $5)$. These findings may have resulted from an increase in RUP availability and increased microbial growth in the PMR+canola cows; however, these measures were not directly assessed in the current study.

A decrease in the lipogenic to gluconeogenic VFA ratio (Auldist et al., 2013) and increases in Butyrivibrio fibrisolvens and Megasphaera spp., which are regarded as major biohydrogenating bacteria in the rumen (OrRashid et al., 2009), have been associated with a lower yield of milk fat. The relative abundance of Butyrivibrio spp. increased and the lipogenic to gluconeogenic VFA ratio decreased with increased feeding amount, along with decreased milk fat percentage, which supports this association, but the relative abundance of Megasphaera spp. was not influenced by feeding amount. We hypothesized that B. fibrisolvens and Megasphaera spp. would 
be increased in relative abundance in the controls fed 14 or $16 \mathrm{~kg}$ of SDM compared with the PMR and PMR+canola cows fed at these amounts, as they had a lower yields of milk fat and tended to have a lower milk fat percentage. However, the relative abundance of Butyrivibrio and Megasphaera spp. was not different in these cows. Ramirez et al. (2012) found no difference in biohydrogenating bacteria in the rumen, despite differences in milk fat percentage and yield. Perhaps these bacteria do not always have the most substantial role in biohydrogenation.

The large among- and within-group variation in $\mathrm{BCC}$, which was evident in the constrained betweengroup $\mathrm{PCoA}$, is consistent with considerable diversity in bacterial populations in ruminants fed identical diets (Brulc et al., 2009; Li et al., 2009; Chen et al., 2012). The apparent host specificity of ruminal bacteria may pose a challenge when examining interventions or management changes that affect the rumen and emphasizes the need for large sample sizes for in vivo studies.

The ruminal BCC in the current study was consistent with known bacterial communities in dairy cattle, as bacteria from the Bacteroidetes (predominately gramnegative) and Firmicutes (predominately gram-positive) phyla appeared to dominate the core bacterial microbiome, regardless of feeding group, consistent with other studies (Khafipour et al., 2009; de Menezes et al., 2011; Jami and Mizrahi, 2012). Similarly, the Prevotella were the dominant ruminal bacterial genus in the current study and others (Tajima et al., 2000; Fernando et al., 2010; Jami and Mizrahi, 2012). However, the relative abundance of bacteria from the Proteobacteria phylum, which have highly diverse metabolic functions (Brenner et al., 2005), was much lower in the current study than generally reported in dairy cows. Knowledge of substrate utilization and end products of members of the candidate phylum TM7, which had the third highest relative abundance in the current study, is limited, but members have been identified in dairy cows (Khafipour et al., 2009; Kong et al., 2010; Hook et al., 2011).

The predominance of the Prevotellaceae, Ruminococcaceae, and Lachnospiraceae bacterial families, regardless of feeding group, is consistent with other studies (de Menezes et al., 2011; Thoetkiattikul et al., 2013; Zened et al., 2013); however, Thoetkiattikul et al. (2013) also reported a large relative abundance of Flavobacteriaceae, which were not observed in the current study. The members of the Prevotellaceae family are gram-negative bacteria that belong to the Bacteroidetes phylum and can utilize a range of substrates (Boone et al., 2011), whereas members of the Ruminococcaceae and Lachnospiraceae families belong to the Firmicutes phylum and are largely cellulolytic and fibrolytic bacteria, respectively (Thoetkiattikul et al., 2013).
Nagaraja and Titgemeyer (2007) state that the relative abundances of gram-negative bacteria are replaced with abundances of gram-positive bacteria during acute ruminal acidosis. However, in our study, the relative abundance of the Prevotellaceae, which represent the dominant gram-negative bacteria, was increased, whereas the abundances of the Ruminococcaceae and the unclassified Clostridiales (gram-positive bacteria) were lower in control cows compared with PMR cows. Zened et al. (2013) also reported a dietary effect on BCC of members of the Prevotellaceae and Ruminococcaceae families, but in contrast to the current study, those authors reported an influence on Lachnospiraceae in cows fed maize silage diets with high or low starch content. A higher relative abundance of Prevotellaceae has been reported in cows fed pasture compared with TMR (de Menezes et al., 2011), a finding consistent with their higher relative abundance in the control cows in the current study. Khafipour et al. (2009) reported a decrease in Prevotella spp. with induced subacute ruminal acidosis, whereas, in the current study, Prevotella were higher in relative abundance in the control cows, which had higher acidosis eigenvalues compared with the PMR cows; Mohammed et al. (2012) found that Prevotella were not directly associated with ruminal acidosis.

The relative abundances of the ruminal bacteria Streptococcus and Lactobacillus, which are associated with ruminal acidosis, and Megasphaera, which are associated with protection against ruminal acidosis, were $<1 \%$ in the current study. The involvement of Streptococcus bovis in ruminal acidosis is unclear; other studies have reported varied effects of starch on the relative abundance of or total bacterial rDNA copies contributed by Strep. bovis (Tajima et al., 2000; Fernando et al., 2010; Palmonari et al., 2010). The cows in the current study were adapted to their feeding groups before rumen sampling and were also supplemented with monensin and tylosin, which may account for the low abundance of Streptococcus and Lactobacillus.

The higher relative abundance of the Veillonellaceae family in the controls is similar to the higher abundance of these bacteria identified in pasture-fed compared with TMR-fed cows (de Menezes et al., 2011). The Veillonellaceae family includes members that produce propionate as their major fermentation product (Strobel and Russell, 1991), which is consistent with the current study. Some bacterial species belonging to the Veillonellaceae family utilize lactate (Stewart et al., 1997).

The Erysipelotrichaceae family, which had a higher relative abundance in control cows, is more abundant in pasture-fed compared with TMR-fed cows (de Menezes et al., 2011), possibly reflecting the higher pasture DMI 
of the control cows in the current study, although the role of this family in ruminal microbial fermentation is unknown (Verbarg et al., 2004; de Menezes et al., 2011). Literature on the involvement of bacteria from the following families in ruminal acidosis is limited: F16, Coriobacteriaceae, Anaerolinaceae, Clostridiales Family XIII incertae sedis, Catabacteriaceae, Bacillaceae, and Acetobacteraceae, but these ruminal bacteria warrant further investigation.

The increase in dietary starch content with increasing supplement feeding amount was expected to decrease the number of fibrolytic bacteria, including members of the Ruminococcaceae and Fibrobacteraceae families (Tajima, 2001; Zened et al., 2013). This finding was consistent with observations for the Ruminococcaceae but in contrast to the increase in relative abundance of bacteria from the Fibrobacteraceae family.

Studies of the effects of protein on ruminal BCC are limited. The relative abundance of bacteria belonging to the Prevotella, Butyrivibrio, and Streptococcus genera that contain proteolytic bacteria were not affected by increased dietary protein in the current study. The only ruminal bacterial families that were influenced in the high supplement feeding amounts analysis that incorporated the effect of protein were the F16, Veillonellaceae, and Acetobacteraceae, and further research is required to investigate their involvement in ruminal function.

Assessment of the microbiome by meta-transcriptomics, as suggested by Mullins et al. (2013), would allow examination of metabolic shifts occurring during dietary changes and may be beneficial in broadening our understanding of ruminal responses to dietary changes. Investigations into the interactions of ruminal bacteria, protozoa, archaea, bacteriophages, and fungi, and associations with ruminal acidosis may be beneficial.

\section{CONCLUSIONS}

First, as hypothesized, cows fed diets as a PMR, with or without canola meal, had improved ruminal measures, distinct ruminal BCC, and a decreased incidence of ruminal acidosis compared with controls fed isoenergetic diets as individual feed components. However, milk measures were only increased in the cows fed PMR+canola. Second, as hypothesized, a linear increase in supplement feeding amount from 8 to $16 \mathrm{~kg}$ of $\mathrm{DM} /$ cow per day of total supplement altered milk and ruminal measures, created a distinct ruminal BCC, and increased the incidence of ruminal acidosis. These measures were also associated with each other. In conclusion, feeding diets as a PMR may benefit ruminal conditions and reduce the incidence of ruminal acidosis, regardless of feeding amount up to $16 \mathrm{~kg}$ of DM of total supplement/cow per day but did not result in increased milk measures compared with isoenergetic control diets fed as components in late-lactation cows. Feeding protein above dietary requirements may provide milk production and milk composition benefits; however, further research is warranted.

\section{ACKNOWLEDGMENTS}

The authors acknowledge staff at the Department of Environment and Primary Industries (Ellinbank, VIC, Australia) for provision of ruminal fluid samples and milk measures data. This work was supported by Department of Environment and Primary Industries (VIC, Australia), Dairy Australia (Southbank, VIC, Australia), SBScibus (Camden, NSW, Australia), DairyNSW (Mudgee, NSW, Australia), The CSIRO Animal, Food and Health Services (St. Lucia, QLD, Australia), and The University of Sydney (Camden, NSW, Australia). The authors also acknowledge the staff at CSIRO Animal, Food and Health Services (St. Lucia, QLD, Australia) for laboratory assistance, in particular Vicki Whan.

\section{REFERENCES}

Allen, M. S., J. A. Voelker, and M. Oba. 2006. Physically effective fibre and regulation of ruminal $\mathrm{pH}$ : More than just chewing. Pages 270-278 in Production Diseases in Farm Animals. N. P. Joshi and T. H. Herdt, ed. Wageningen Academic Publishers, Wageningen, the Netherlands.

AOAC International. 2000. Official Methods of Analysis. 17th ed. AOAC International, Arlington, VA.

Auldist, M. J., L. C. Marett, J. S. Greenwood, M. Hannah, J. L. Jacobs, and W. J. Wales. 2013. Effects of different strategies for feeding supplements on milk production responses in cows grazing a restricted pasture allowance. J. Dairy Sci. 96:1218-1231.

Auldist, M. J., L. C. Marett, J. S. Greenwood, M. M. Wright, M. Hannah, J. L. Jacobs, and W. J. Wales. 2014. Replacing wheat with canola meal in a partial mixed ration increases the milk production of cows grazing at a restricted pasture allowance in spring. Anim. Prod. Sci. 54:869-878.

Bargo, F., L. D. Muller, J. E. Delahoy, and T. W. Cassidy. 2002a. Performance of high producing dairy cows with three different feeding systems combining pasture and total mixed rations. J. Dairy Sci. 85:2948-2963.

Bargo, F., L. D. Muller, E. S. Kolver, and J. E. Delahoy. 2003. Invited review: Production and digestion of supplemented dairy cows on pasture. J. Dairy Sci. 86:1-42.

Bargo, F., L. D. Muller, G. A. Varga, J. E. Delahoy, and T. W. Cassidy. 2002b. Ruminal digestion and fermentation of high-producing dairy cows with three different feeding systems combining pasture and total mixed rations. J. Dairy Sci. 85:2964-2973.

Boone, D. R., R. W. Castenholz, G. M. Garrity, and N. R. Krieg. 2011. Bergey's Manual of Systematic Bacteriology: Vol. 4: The Bacteroidetes, Spirochaetes, Tenericutes (Mollicutes), Acidobacteria, Fibrobacteres, Fusobacteria, Dictyoglomi, Gemmatimonadetes, Lentisphaerae, Verrucomicrobia, Chlamydiae, and Planctomycetes. Springer, New York, NY.

Bragg, L., G. Stone, M. Imelfort, P. Hugenholtz, and G. W. Tyson. 2012. Fast, accurate error-correction of amplicon pyrosequences using Acacia. Nat. Methods 9:425-426.

Bramley, E., I. J. Lean, W. J. Fulkerson, and N. D. Costa. 2012. Feeding management and feeds on dairy farms in New South Wales and Victoria. Anim. Prod. Sci. 52:20-29. 
Bramley, E., I. J. Lean, W. J. Fulkerson, M. A. Stevenson, A. R. Rabiee, and N. D. Costa. 2008. The definition of acidosis in dairy herds predominantly fed on pasture and concentrates. J. Dairy Sci. 91:308-321.

Brenner, D. J., N. R. Krieg, and J. T. Staley. 2005. Bergey's Manual of Systematic Bacteriology: Vol 2: The Proteobacteria: Part C: The Alpha-, Beta-, Delta-, and Epsilonproteobacteria. Springer, New York, NY.

Brulc, J. M., D. A. Antonopoulos, M. E. Berg Miller, M. K. Wilson, A. C. Yannarell, E. A. Dinsdale, R. E. Edwards, E. D. Frank, J. B. Emerson, P. Wacklin, P. M. Coutinho, B. Henrissat, K. E. Nelson, and B. A. White. 2009. Gene-centric metagenomics of the fiber-adherent bovine rumen microbiome reveals forage specific glycoside hydrolases. Proc. Natl. Acad. Sci. USA 106:1948-1953.

Callaway, T. R., S. E. Dowd, T. S. Edrington, R. C. Anderson, N Krueger, N. Bauer, P. J. Kononoff, and D. J. Nisbet. 2010. Evaluation of bacterial diversity in the rumen and feces of cattle fed different levels of dried distillers grains plus solubles using bacterial tag-encoded FLX amplicon pyrosequencing. J. Anim. Sci. 88:3977-3983.

Caporaso, J. G., J. Kuczynski, J. Stombaugh, K. Bittinger, F. D. Bushman, E. K. Costello, N. Fierer, A. G. Pena, J. K. Goodrich, J. I. Gordon, G. A. Huttley, S. T. Kelley, D. Knights, J. E. Koenig, R. E. Ley, C. A. Lozupone, D. McDonald, B. D. Muegge, M. Pirrung, J. Reeder, J. R. Sevinsky, P. J. Turnbaugh, W. A. Walters, J. Widmann, T. Yatsunenko, J. Zaneveld, and R. Knight. 2010 QIIME allows analysis of high-throughput community sequencing data. Nat. Methods 7:335-336.

Carberry, C. A.. D. A. Kenny, S. Han, M. S. McCabe, and S. M. Waters. 2012. Effect of phenotypic residual feed intake and dietary forage content on the rumen microbial community of beef cattle. Appl. Environ. Microbiol. 78:4949-4958.

Chen, Y., M. Oba, and L. L. Guan. 2012. Variation of bacterial communities and expression of toll-like receptor genes in the rumen of steers differing in susceptibility to subacute ruminal acidosis. Vet. Microbiol. 159:451-459.

de Menezes, A. B., E. Lewis, M. O'Donovan, B. F. O'Neill, N. Clipson, and E. M. Doyle. 2011. Microbiome analysis of dairy cows fed pasture or total mixed ration diets. FEMS Microbiol. Ecol. 78:256-265.

Dennis, S. M., T. G. Nagaraja, and E. E. Bartley. 1981. Effect of lasalocid or monensin on lactate-producing or using rumen bacteria. J. Anim. Sci. 52:418-426.

Dray, S., and A.-B. Dufour. 2007. The ade4 package: Implementing the duality diagram for ecologists. J. Stat. Softw. 22:1-20.

Fernando, S. C., H. T. Purvis, F. Z. Najar, L. O. Sukharnikov, C. R. Krehbiel, T. G. Nagaraja, B. A. Roe, and U. Desilva. 2010. Rumen microbial population dynamics during adaptation to a high-grain diet. Appl. Environ. Microbiol. 76:7482-7490.

Golder, H. M., P. Celi, A. R. Rabiee, C. Heuer, E. Bramley, S. W Miller, R. King, and I. J. Lean. 2012. Effects of grain, fructose and histidine on ruminal $\mathrm{pH}$ and fermentation products during an induced subacute acidosis protocol. J. Dairy Sci. 95:1971-1982.

Golder, H. M., P. Celi, A. R. Rabiee, and I. J. Lean. 2014a. Effects of feed additives on rumen and blood profiles during a starch and fructose challenge. J. Dairy Sci. 97:985-1004.

Golder, H. M., S. E. Denman, C. McSweeney, P. Celi, and I. J. Lean 2014b. Ruminal bacterial community shifts in grain, sugar, and histidine challenged dairy heifers. J. Dairy Sci. 97:5131-5150. http://dx.doi.org/10.3168/jds.2014-8003.

Greenwood, J. S., M. J. Auldist, L. C. Marett, M. C. Hannah, J. L. Jacobs, and W. J. Wales. 2014. Ruminal pH and whole-tract digestibility in dairy cows consuming fresh cut herbage plus concentrates and silage fed either separately or as a partial mixed ration. Anim. Prod. Sci. http://dx.doi.org/10.1071/AN12406.

Hook, S. E., M. A. Steele, K. S. Northwood, J. Dijkstra, J. France, A.-D. G. Wright, and B. W. McBride. 2011. Impact of subacute ruminal acidosis (SARA) adaptation and recovery on the density and diversity of bacteria in the rumen of dairy cows. FEMS Microbiol. Ecol. 78:275-284.
Hughes, J. B., J. J. Hellmann, T. H. Ricketts, and B. J. M. Bohannan. 2001. Counting the uncountable: Statistical approaches to estimating microbial diversity. Appl. Environ. Microbiol. 67:4399-4406.

Huhtanen, P., M. Hetta, and C. Swensson. 2011. Evaluation of canola meal as a protein supplement for dairy cows: A review and a metaanalysis. Can. J. Anim. Sci. 91:529-543.

Hungate, R. E. 1966. The Rumen and its Microbes. Academic Press Inc., New York, NY.

Hungate, R. E., R. W. Dougherty, M. P. Bryant, and R. M. Cello. 1952. Microbiological and physiological changes associated with acute indigestion in sheep. Cornell Vet. 42:423-449.

Jami, E., and I. Mizrahi. 2012. Composition and similarity of bovine rumen microbiota across individual animals. PLoS ONE 7:e33306.

Khafipour, E., S. Li, J. C. Plaizier, and D. O. Krause. 2009. Rumen microbiome composition determined using two nutritional models of subacute ruminal acidosis. Appl. Environ. Microbiol. 75:7115-7124.

Khorasani, G. R., E. K. Okine, and J. J. Kennelly. 2001. Effects of substituting barley grain with corn on ruminal fermentation characteristics, milk yield, and milk composition of Holstein cows. J. Dairy Sci. 84:2760-2769.

Kim, M., M. Morrison, and Z. Yu. 2011. Status of the phylogenetic diversity census of ruminal microbiomes. FEMS Microbiol. Ecol. 76:49-63.

Kong, Y., R. Teather, and R. Forster. 2010. Composition, spatial distribution, and diversity of the bacterial communities in the rumen of cows fed different forages. FEMS Microbiol. Ecol. 74:612-622.

Lane, D. J. 1991. 16S/23S rRNA sequencing. Pages 115-175 in Nucleic Acid Techniques in Bacterial Systematics. Vol. 4. E. Stackebrandt and M. Goodfellow, ed. John Wiley \& Son Ltd., New York, NY.

Leddin, C. M., C. R. Stockdale, J. Hill, J. W. Heard, and P. T. Doyle. 2010. Increasing amounts of crushed wheat fed with Persian clover herbage reduced ruminal $\mathrm{pH}$ and dietary fibre digestibility in lactating dairy cows. Anim. Prod. Sci. 50:837-846.

Li, M., G. B. Penner, E. Hernandez-Sanabria, M. Oba, and L. L. Guan. 2009. Effects of sampling location and time, and host animal on assessment of bacterial diversity and fermentation parameters in the bovine rumen. J. Appl. Microbiol. 107:1924-1934.

Martineau, R., D. R. Ouellet, and H. Lapierre. 2013. Feeding canola meal to dairy cows: A meta-analysis on lactational responses. J. Dairy Sci. 96:1701-1714.

Mohammed, R., D. M. Stevenson, P. J. Weimer, G. B. Penner, and K. A. Beauchemin. 2012. Individual animal variability in ruminal bacterial communities and ruminal acidosis in primiparous Holstein cows during the periparturient period. J. Dairy Sci. 95:6716-6730.

Mullins, C. R., L. K. Mamedova, A. J. Carpenter, Y. Ying, M. S. Allen, I. Yoon, and B. J. Bradford. 2013. Analysis of rumen microbial populations in lactating dairy cattle fed diets varying in carbohydrate profiles and Saccharomyces cerevisiae fermentation product. J. Dairy Sci. 96:5872-5881.

Nagaraja, T. G., and E. C. Titgemeyer. 2007. Ruminal acidosis in beef cattle: The current microbiological and nutritional outlook. J. Dairy Sci. 90(E-Suppl.):E17-E38.

NRC. 2001. Nutrient Requirements of Dairy Cattle. 7th ed. Natl. Acad. Press, Washington, DC.

O'Grady, L., M. L. Doherty, and F. J. Mulligan. 2008. Subacute ruminal acidosis (SARA) in grazing Irish dairy cows. Vet. J. 176:4449.

Oldham, J. D. 1984. Protein-energy interrelationships in dairy cows. J. Dairy Sci. 67:1090-1114

Or-Rashid, M. M., T. C. Wright, and B. W. McBride. 2009. Microbial fatty acid conversion within the rumen and the subsequent utilization of these fatty acids to improve the healthfulness of ruminant food products. Appl. Microbiol. Biotechnol. 84:1033-1043.

Packer, E. L., E. H. Clayton, and P. M. V. Cusack. 2011. Rumen fermentation and liveweight gain in beef cattle treated with monensin and grazing lush forage. Aust. Vet. J. 89:338-345.

Palmonari, A., D. M. Stevenson, D. R. Mertens, C. W. Cruywagen, and P. J. Weimer. 2010. pH dynamics and bacterial community 
composition in the rumen of lactating dairy cows. J. Dairy Sci. 93:279-287.

Pers-Kamczyc, E., P. Zmora, A. Cieślak, and M. Szumacher-Strabel. 2011. Development of nucleic acid based techniques and possibilities of their application to rumen microbial ecology research. J. Anim. Feed Sci. 20:315-337.

Ramirez, H. A. R., K. Nestor, L. O. Tedeschi, T. R. Callaway, S. E. Dowd, S. C. Fernando, and P. J. Kononoff. 2012. The effect of brown midrib corn silage and dried distillers' grains with solubles on milk production, nitrogen utilization and microbial community structure in dairy cows. Can. J. Anim. Sci. 92:365-380.

Snell-Castro, R., J.-J. Godon, J.-P. Delgenès, and P. Dabert. 2005. Characterization of the microbial diversity in a pig manure storage pit using small subunit rDNA sequence analysis. FEMS Microbiol. Ecol. 52:229-242.

Stewart, C. S., J. F. Flint, and M. P. Bryant. 1997. The rumen bacteria. Pages 10-72 in The Rumen Microbial Ecosystem. 2nd ed. P. N. Hobson and C. S. Stewart, ed. Blackie Academic and Professional, London, UK.

Stockdale, C., A. Callaghan, and T. Trigg. 1987. Feeding high energy supplements to pasture-fed dairy cows. Effects of stage of lactation and level of supplement. Aust. J. Agric. Res. 38:927-940.

Strobel, H. J., and J. B. Russell. 1991. Succinate transport by a ruminal selenomonad and its regulation by carbohydrate availability and osmotic strength. Appl. Environ. Microbiol. 57:248-254.

Sutton, J. D. 1984. Feeding and milk fat production. Pages $43-52$ in Milk Compositional Quality and its Importance in Future Markets. M. E. Casde and R. G. Gunn, ed. Occ. Publ. 9. Br. Soc. Anim. Prod., Penicuik, UK.

Tajima, K. 2001. Diet-dependent shifts in the bacterial population of the rumen revealed with real-time PCR. Appl. Environ. Microbiol. 67:2766-2774.
Tajima, K., S. Arai, K. Ogata, T. Nagamine, H. Matsui, M. Nakamura, R. I. Aminov, and Y. Benno. 2000. Rumen bacterial community transition during adaptation to high-grain diet. Anaerobe $6: 273-284$.

Thoetkiattikul, H., W. Mhuantong, T. Laothanachareon, S. Tangphatsornruang, V. Pattarajinda, L. Eurwilaichitr, and V. Champreda. 2013. Comparative analysis of microbial profiles in cow rumen fed with different dietary fiber by tagged $16 \mathrm{~S}$ rRNA gene pyrosequencing. Curr. Microbiol. 67:130-137.

Tyrrell, H. F., and J. T. Reid. 1965. Prediction of the energy value of cow's milk. J. Dairy Sci. 48:1215-1223.

Verbarg, S., H. Rheims, S. Emus, A. Frühling, R. M. Kroppenstedt, E. Stackebrandt, and P. Schumann. 2004. Erysipelothrix inopinata sp. nov., isolated in the course of sterile filtration of vegetable peptone broth, and description of Erysipelotrichaceae fam. nov. Int. J. Syst. Evol. Microbiol. 54:221-225.

Weimer, P. J., D. M. Stevenson, D. R. Mertens, and E. E. Thomas. 2008. Effect of monensin feeding and withdrawal on populations of individual bacterial species in the rumen of lactating dairy cows fed high-starch rations. Appl. Microbiol. Biotechnol. 80:135-145.

Weimer, P. J., D. M. Stevenson, H. C. Mantovani, and S. L. C. Man. 2010. Host specificity of the ruminal bacterial community in the dairy cow following near-total exchange of ruminal contents. J. Dairy Sci. 93:5902-5912.

Zened, A., S. Combes, L. Cauquil, J. Mariette, C. Klopp, O. Bouchez, A. Troegeler-Meynadier, and F. Enjalbert. 2013. Microbial ecology of the rumen evaluated by 454 GS FLX pyrosequencing is affected by starch and oil supplementation of diets. FEMS Microbiol. Ecol. 83:504-514. 